\title{
Changes in temperature and rainfall extremes across East Asia in the CMIP5 ensemble
}

\author{
Youngsaeng Lee ${ }^{1,3} \quad$ Jayeong Paek ${ }^{2,3} \quad$ Jeong-Soo Park ${ }^{3, *}$ \\ Kyung-On Boo ${ }^{4}$ \\ 1: Digital Transformation Department, Korea Electric Power Corporation, Korea \\ 2: Institute for Biomedical Science, Chonnam National University Hwasun Hospital, Korea \\ 3: Department of Statistics, Chonnam National University, Gwangju 500-757, Korea \\ 4: Korea Meteorological Administration, Korea \\ *: Corresponding author, E-mail: jspark@jnu.ac.kr, Tel: +82-62-530-3445
}

Feb 2020

\begin{abstract}
${ }^{1}$ We analyze annual extremes of daily maximum and minimum surface air temperature and of daily rainfall in East Asia and the Korean peninsula. This study made intensive use of the simulation data available from the CMIP5 (Coupled Model Intercomparison Project Phase 5) multimodels in historical and future experiments up to year 2100, employing three different radiative forcings: $\mathrm{RCP} 2.6, \mathrm{RCP} 4.5$, and RCP8.5 (representative concentration pathways). Several reanalysis datasets are used to compare and evaluate the simulated climate extremes in the late 20th century. We estimate the future changes in precipitation and temperature extremes in East Asia and Korea, and compare them to the global result, for the reference period 1986-2005. The rising rate of future cold extremes over East Asia and Korea is faster than that of warm extremes. This phenomenon appears more distinctly in Korea as a local scale, indicating more sensitivity of the Korean penisula to global warming. The increase of the 20-year return level of maximum precipitation in the CMIP5 over East Asia by the end of 21st century are about $7 \%$ in the RCP2.6, $15 \%$ in the RCP 4.5 , and $35 \%$ in the RCP 8.5 experiments, which exceed the corresponding global values. We also estimate the changes in precipitation extremes across East Asia as a function of the annual mean temperature variation at the same location. The CMIP5 sensitivity in maximum precipitation across East Asia is $5.5 \% /{ }^{\circ} \mathrm{C}$, which is lower than the
\end{abstract}

\footnotetext{
${ }^{1}$ This manuscript is the authors' version before publication in Theoretical and Applied Climatology 2020. doi:10.1007/s00704-020-03180-w
} 
global figure $\left(5.8 \% /{ }^{\circ} \mathrm{C}\right)$. The sensitivity for the Korean peninsula is $7.38 \% /{ }^{\circ} \mathrm{C}$, indicating the strong impact of global warming to Korea. The results will be important in mitigating the detrimental effects of variations of climatic extremes and in improving the regional strategy for water resource and eco-environmental management, particulaly for such areas in East Asia under significant changes in temperature and rainfall extremes.

Keywords: Annual maximum daily precipitation; Annual extremes of temperature; Generalized extreme value distribution; Multimodel median; Relative change; Taylor diagram.

\section{Introduction}

Over the last century, the global mean surface temperature has risen. The climate has changed both in terms of the average conditions as well as variability and extreme events. Variations in immoderate climate have received much attention because of their high impact on the wellbeing of human and natural systems and because of relatively larger uncertainties than changes in means. Many studies (e.g., Alexander et al 2006; Tebaldi et al 2006; Sillmann et al 2013; AghaKouchak et al 2013; Alexander 2015) have reported globally observed long-term changes in temperature and rainfall extremes. The Special Report on Extreme Events (Seneviratne et al 2012) emphasized that future changes in very severe climate are expected to be substantial, especially in temperature extremes.

Regional climate change results from complex processes that vary with location and show different responses to the global-scale change (IPCC AR5, 2013). Using coupled simulation models, many studies (e.g., Fowler and Ekstrom 2009; Zhang et al 2011; Fischer et al 2012; Thibeault and Seth 2014; Jiang et al 2017) have shown that ranges in changes of extreme climate vary regionally and are diverse under different emission scenarios. Detailed information regarding climate change at regional and local levels is fundamentally necessary for a better understanding of the observed variations, as well as for more effective adaptation to and risk management of future climate changes. East Asia (EA) is a populous region, and it is crucial to assess the changes in extreme meteorological events in this region under different climatic change scenarios. EA is considered by many authors (e.g., Ho et al 2011; Zhou et al 2014; Freychet et al 2015; Li et al 2018; Kwon et al 2019) to be one of the regions most vulnerable to future increases in very abnormal weather and climate under global warming. For example, projected changes in extreme precipitation indices over the Asian monsoon domain are larger than over other monsoon domain, indicating the strong sensitivity of Asian monsoon to global warming (Kitoh et al 2013).

Ho et al (2011), Wu et al (2016), Park et al (2016), Niu et al (2018), and Park and Min 
(2019) projected climate extremes in EA using ensemble of multiple "regional" climate models. The results predict that overall increases in temperature and heavy rainfall in EA. Their results indicate that temperature increases involve an overall shift of the daily temperature distribution toward warmer conditions while precipitation rises are due to dominant increases in moderate-heavy rainfall events. They also predict an increase of consecutive dry days over EA which will enhance the risk of drought disasters in the future. Kitoh et al (2013), Zhou et al (2014), and Freychet et al $(2015,2016)$ predicted future climate extremes over EA using ensemble of the CMIP5 (Coupled Model Intercomparison Project Phase 5) multimodels. They reported that substantial changes are projected in temperature and precipitation extremes under different emission scenarios, compared to the reference period 1986-2005. These changes include a decrease in cold extremes, an increase in hotter temperature, and an intensification of precipitation extremes.

Kharin et al (2013), which is an update of Kharin et al (2007), provided an analysis of global temperature and rainfall extremes in the CMIP5 multimodel ensemble. They estimated 20-year return levels of annual extremes of temperature and daily rainfall as simulated by the CMIP5 codes in the late 20th century in the historical experiments. Furthermore, they compared them with estimates based on the reanalysis data, and evaluated their projected changes by the end of the 21st century under various radiative forcing scenarios. Since their target area and result are mainly at the global level, the regional analysis is confined. Thus, we concentrate on similar research on EA and the Korean peninsula, and detailed results with comparisons to the global values are provided in this study.

The datasets, methodology, simulation codes, and periods of interest considered in this study are similar to Kharin et al's (2013) (hereafter referred to as K13). The differences are the study region, new work for model assessment, and comparison with the global values. The methodological details are minimally described in this paper. For all specifics, we refer to the Supplementary Material of this study and of K13. The main focus of the description here is the regionally detailed result we obtained for EA and for the Korean peninsula.

Figure 1 is a map of East Asia showing the study region from $99^{\circ}$ to $156^{\circ}$ longitude and from $19.5^{\circ}$ to $60^{\circ}$ latitude, including sea and land, with grid cells of $1.5^{\circ} \times 1.5^{\circ}$ and coverage for the Korean peninsula. In total, $39 \times 28=1,092$ grid cells including 23 for the Korean peninsula are considered.

The remainder of the paper is structured as follows. The datasets and numerical models are described in Section 2. The statistical methods are briefly mentioned in Section 3. Section 4 compares simulated extremes with observational evidence. Projected future changes are presented in Section 5. A summary is given in Section 6 followed by discussion in Section 7 . The details including technical specifics and some figures are available in the accompanying 


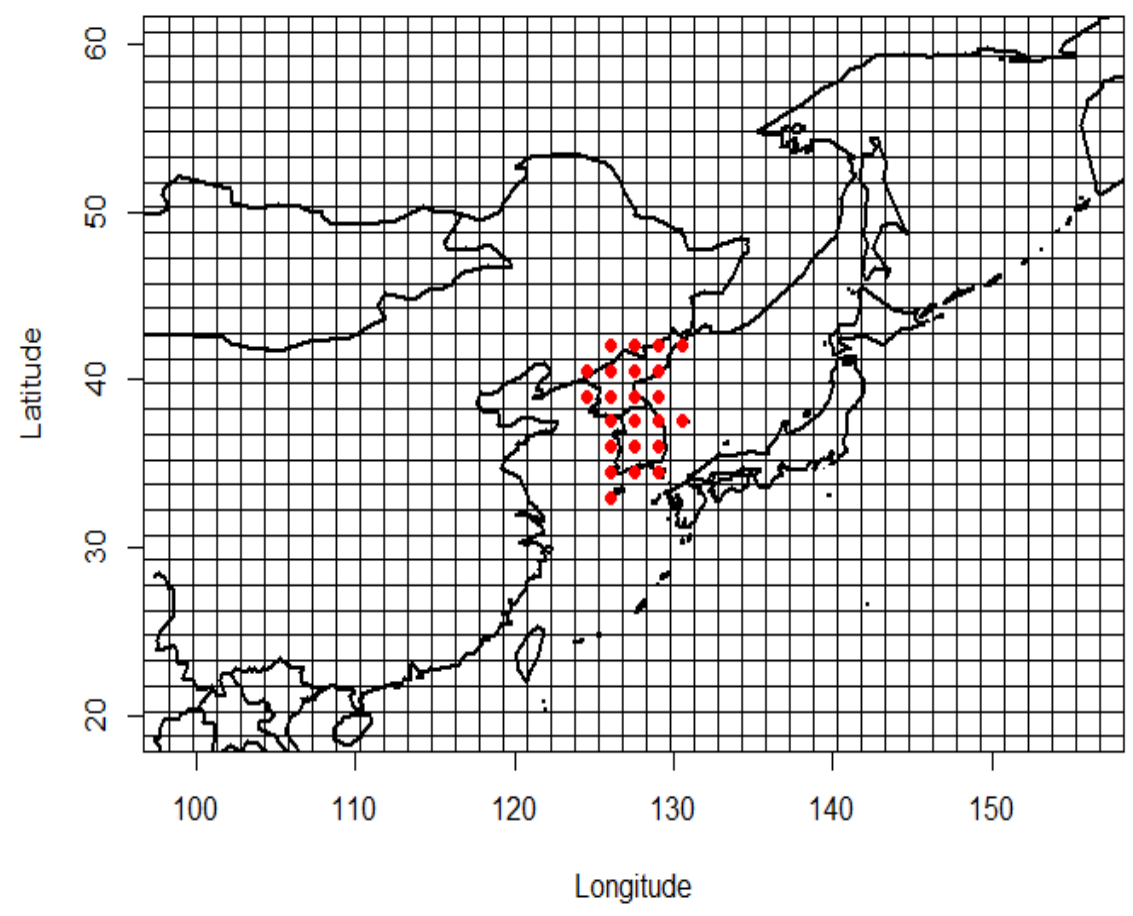

Figure 1: Map of East Asia from $99^{\circ}$ to $156^{\circ}$ longitude and $19.5^{\circ}$ to $60^{\circ}$ latitude including sea and land, with grid cells of $1.5^{\circ} \times 1.5^{\circ}$ and coverage for the Korean peninsula.

Supplementary Material (hereafter referred to as the SM).

\section{Datasets and simulation models}

We analyze the following four major variables with notations:

$T X=$ the annual warmest among daily maximum surface air temperatures,

$T N=$ the annual coldest among daily minimum surface air temperatures,

$R=$ the annual largest among the daily rainfall amount, and

$R^{5}=$ the annual largest among the 5-day rainfall amount.

Simulation data are obtained from the CMIP5 models in the historical experiment (years 1850-2005) and the experiments for the 21st century (years 2006-2100) employing three different radiative forcings. The considered scenarios are RCP2.6, RCP4.5, and RCP8.5 (Represen- 
tative Concentration Pathways; Moss et al. 2010). The estimated radiative forcing values by year 2100 are $2.6 \mathrm{Wm}^{-2}, 4.5 \mathrm{Wm}^{-2}$ and $8.5 \mathrm{Wm}^{-2}$ in the RCP2.6, RCP4.5 and RCP8.5 experiments, respectively. The CMIP5 daily output was available for 29 models for the historical experiment, 21 for the RCP2.6, 28 for the RCP4.5, and 25 models for the RCP8.5 scenario. For the details, see Tables S1 and S2 in the SM, in which the CMIP5 climate models analyzed in this study and their resolutions are listed.

Several observationally constrained (or reanalysis) datasets are employed to evaluate simulated climate extremes in the late 20th century climate. A main dataset used in this study is the European Centre for Medium-Range Weather Forecasts Re-Analysis-Interim (Dee et al 2011), abbreviated as ERA-Interim or ERA-I. Other collections utilized for comparison are ERA40, NCEP1, NCEP2, CMAP, and GPCP. For the detailed list of the six reanalysis datasets including references, see Table S3 in the SM.

\section{Methodology}

The major measurements of interest in this study are the return level of annual extremes and the corresponding waiting time. A return level for a specified T-year waiting time (or return period) is the value exceeded by an annual extreme with probability $p=1 / T$. Most of the analysis presented here is performed for the 20-year waiting time or, equivalently, for an annual exceedance probability of $p=0.05$. These 20-year return levels are denoted by $T X_{20}, T N_{20}$, $R_{20}$, and $R_{20}^{5}$ in this study for annual warmest and coldest temperatures, and for annual largest daily and 5-day rainfalls, respectively. These values are determined as the percentiles of the generalized extreme value (GEV) distribution that is fitted by the L-moments method (Hosking 1990) to samples of climate extremes at every grid cell.

For the ensemble prediction, the simple (or equally weighted) average and the median of the statistics calculated from the multimodels are employed in this study. The terms 'CMIP5 ensemble' and 'CMIP5 median' stand for the simple average and the median obtained based on the CMIP5 multimodels, respectively.

For evaluating the performance of simulation models, we applied the Taylor diagram (Taylor, 2001). The Taylor diagram quantifies the degree of correspondence between the modeled and observed behavior in terms of correlation coefficient, the ratio of the normalized root mean squared error and the normalized standard deviation. See Figure S1 in the SM.

The projected changes in return levels and in waiting times are determined and expressed relative to the climate extremes simulated in the reference period, 1986-2005. The projected multimodel median changes are tested with the Wilcoxon signed-rank statistic. The timedependent GEV distribution is fitted by the maximum likelihood estimation for data in over- 
lapping 51-year time windows. We also estimate the dependence of local changes in maximum precipitation on mean temperature rise by a linear regression method. For more technical details, readers are recommended to see the SM.

\section{Simulated late 20th century climate extremes over East Asia}

\subsection{Temperature extremes}

The left panels in Figure 2 display the CMIP5 ensembles (simple averages) of $R_{20}, T N_{20}$, and $T X_{20}$ calculated from historical data for 1986-2005. In the middle and bottom left maps, the CMIP5 ensemble of $T N_{20}\left(T X_{20}\right)$ across EA is $-9.7^{\circ} \mathrm{C}\left(31.3^{\circ} \mathrm{C}\right)$, which is $9.2^{\circ} \mathrm{C}$ lower $\left(5.1^{\circ} \mathrm{C}\right.$ higher) than the global value, $-0.5^{\circ} \mathrm{C}\left(26.1^{\circ} \mathrm{C}\right)$.

The middle and bottom right panels show the differences of the two 20-year return levels calculated from the CMIP5 historical data and from ERA-I. The difference (CMIP5 minus ERA-I $)$ in the coldest temperature $\left(-2.2^{\circ} \mathrm{C}\right)$ is larger than that in the warmest temperature $\left(0.58^{\circ} \mathrm{C}\right)$. The difference of warm extreme is a bit higher than or similar to the global value (about $0.5^{\circ} \mathrm{C}$ ), while the value of cold extreme is far lower than the global result (about $0.5^{\circ} \mathrm{C}$ ) in $\mathrm{K} 13$. Table $\mathrm{S} 4$ in the $\mathrm{SM}$ provides three quartiles of regionally averaged $T X_{20}$ and $T N_{20}$, which were computed from the CMIP5 historical data for 1986-2005 over the Korean peninsula, EA, and globally. The medians from ERA-I and NCEP2 are also given. The warm extremes from the CMIP5 ensemble across EA and Korea tend to be higher than the global extremes, and the cold extremes across EA are lower than the Korean and global values. The warm extremes from ERA-I and NCEP2 are similar across EA and Korea.

The difference for $T N$ between high and low latitudes is bigger than that for $T X$, which shows the larger natural variability of temperature in winter than that in summer. In addition, the difference between the two extreme temperatures $(T X-T N)$ gets larger as the latitude increases, which reflects that the annual temperature variation in higher latitudes is bigger than that in lower latitudes.

\subsection{Maximum precipitation}

The CMIP5 ensemble of the 20-year return level of the daily maximum precipitation for 19862005 in EA are displayed in the top left panel of Figure 2. The CMIP5 ensemble of $R_{20}$ across EA is about $79.3 \mathrm{~mm} /$ day while the global value is $61 \mathrm{~mm} /$ day as reported in K13. There is good agreement in the maximum precipitation between the CMIP5 ensemble and ERA-I with a 1.02 ratio, as shown in the top right panel of Figure 2 .

Three quartiles from the CMIP5 and median values for the reanalysis are provided in Table 
R20 , CMIP5(1986-2005), 79.321mm day-1

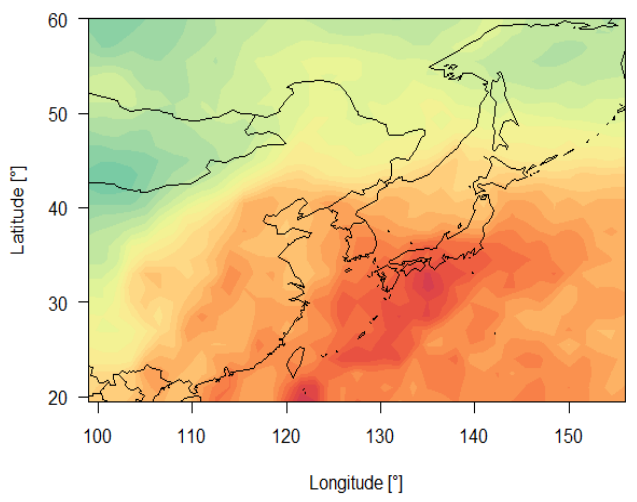

TN20 CMIP5(1986-2005) -9.72

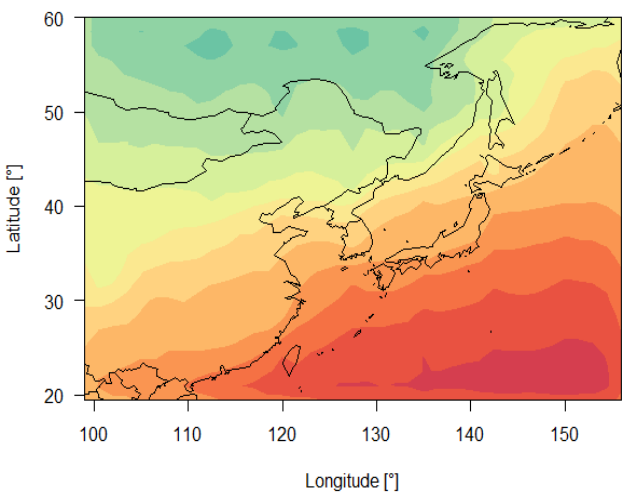

TX20 CMIP5(1986-2005) 31.265

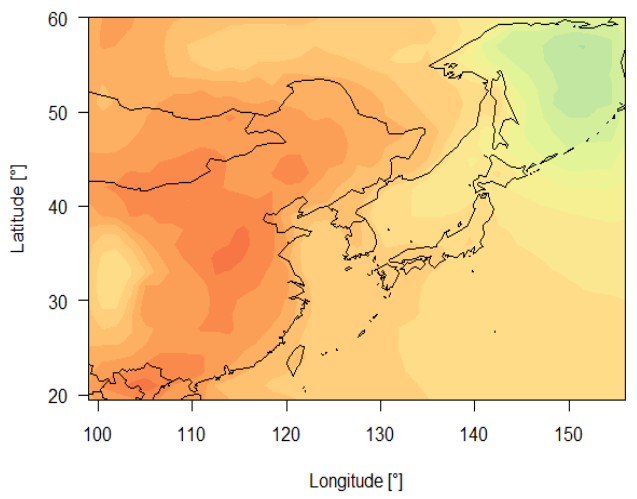

R20 , CMIP5/ERA, 1.016

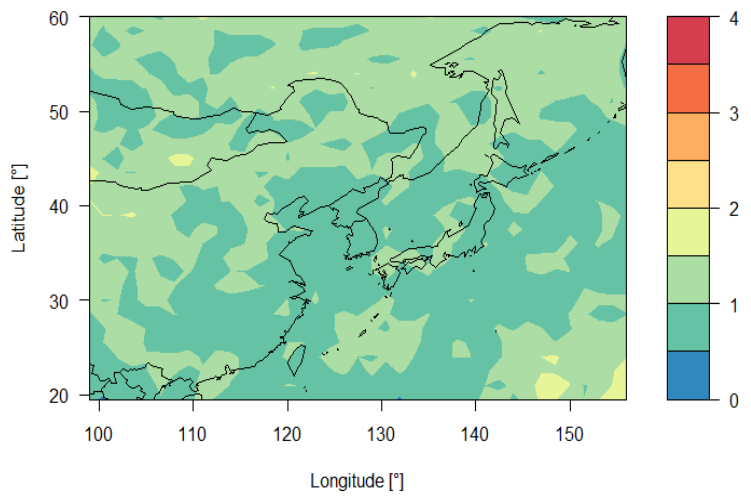

TN20 CMIP5 - ERA(1986-2005) -2.177

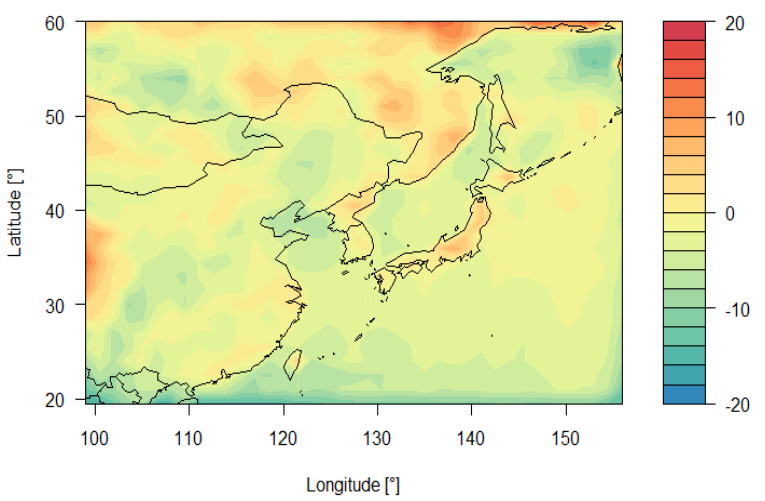

TX20 CMIP5 - ERA(1986-2005) 0.581

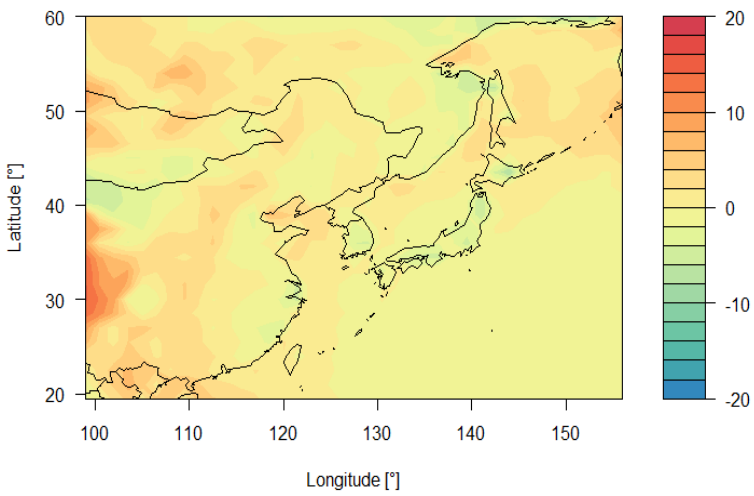

Figure 2: Left panels: The CMIP5 ensembles (simple averages) of 20-year return levels of annual maximum precipitation, annual coldest and annual warmest temperatures for 19862005. Top right panel: The ratio of two 20-year return levels $\left(m m\right.$ day $\left.^{-1}\right)$ of precipitation extremes calculated from CMIP5 historical data and from ERA-Interim reanalysis data. Middle and bottom right panels: Difference of 20-year return levels $\left({ }^{\circ} \mathrm{C}\right)$ of temperature extremes calculated from CMIP5 historical data and from ERA-Interim. 
S5 in the SM. $R_{20}$ of the CMIP5 multimodel for 1986-2005 across EA and Korea tend to be higher than the global values; particularly, $R_{20}$ in Korea is the highest. The $\overline{\mathrm{R}}_{20}^{5}$ computed from CMIP5, ERA-I, and CMAP are in the increasing order of global, EA, and Korea.

Figure S2 in the SM shows the zonally averaged 20-year return levels of the 1986-2005 annual largest daily rainfall and non-overlapping 5-day mean rainfall, the annual lowest and highest temperatures as simulated by the CMIP5 codes plotted on a log scale. In general, temperature and rainfall extremes tend to decrease as latitude increases. Particularly, cold extremes rapidly decrease from low latitude to high latitude while warm extremes slowly decrease. As presented in the box plot, temperature and rainfall extremes from the reanalysis data are located within the estimates from the CMIP5.

Figure S3 shows contour maps of $R_{20}$ for the reference period (1986-2005) calculated from four different reanalyses (ERA-I, ERA40, NCEP1, and NCEP2) across EA. Figures S4 and S5 are contour maps of the 20-year return level of the annual maximum of 5-day precipitation for the reference period obtained from 6 reanalyses (the above four datasets plus CMAP and GPCP) and from the CMIP5 ensemble for the historical pentad data. The surfaces from CMAP and GPCP are similar, especially across Japan and Korea. In other cases, there are noticeable differences among datasets, which reflect the uncertainty among 6 reanalyses. Thus the assessment of a simulation model and the prediction of relative change depends on the choice of the reference dataset.

\section{Projected future changes in climate extremes over East Asia}

\subsection{Changes in temperature extremes}

Throughout EA, since 1950, daily temperature extremes and heat waves have shown significant changes with more frequent warm events and fewer cold events (Alexander et al 2006). At the end of the 21st century, models project substantial warming in temperature extremes. Regionally, warming trends in EA are projected to be above the global mean. In EA, the daily maximum temperature is expected to increase with shortened waiting times in high-emission scenarios (Seneviratne et al 2012). In this study, we check and update this result.

Table 1 summarizes changes of the CMIP5 median and quartiles (25\% and $75 \%)$ of the 20 year return levels in regionally averaged $\mathrm{TX}_{20}$ and $\mathrm{TN}_{20}$ across the globe, and in EA and Korea in 2081-2100 relative to $1986-2005$. Those are denoted by $\Delta \mathrm{TX}_{20}$ and $\Delta \mathrm{TN}_{20}$ for warmest and coldest temperatures. The largest changes in warm and cold extremes appear in RCP8.5. The increases in cold extremes are larger than those in warm extremes across Korea, EA, and globally. This is consistent with K13 and the IPCC AR5 (the Fifth Assessment Report by

Intergovernmental Panel on Climate Change 2013) that the increase rate in low temperatures is 
Table 1: CMIP5 median changes $\left(\Delta \mathrm{TX}_{20}\right.$ and $\left.\Delta \mathrm{TN}_{20}\right)$ and the corresponding interquartile multimodel range in regionally averaged 20-year return levels of annual coldest and warmest temperatures in 2081-2100 relative to 1986-2005 simulated under three scenarios: RCP2.5, RCP4.5, and RCP8.5.

\begin{tabular}{c|ccc|ccc}
\hline & \multicolumn{3}{|c|}{$\Delta \mathrm{TX}_{20}\left({ }^{\circ} \mathrm{C}\right)$} & \multicolumn{3}{c}{$\Delta \mathrm{TN}_{20}\left({ }^{\circ} \mathrm{C}\right)$} \\
Quartiles & Globe & East Asia & Korea & Globe & East Asia & Korea \\
\hline RCP 2.6 75\% & 1.30 & 1.94 & 1.85 & 1.70 & 1.73 & 2.24 \\
RCP 2.6 50\% & 0.80 & 1.18 & 1.40 & 1.50 & 1.40 & 1.44 \\
RCP 2.6 25\% & 0.70 & 0.77 & 0.94 & 1.10 & 1.05 & 1.10 \\
\hline RCP 4.5 75\% & 2.10 & 2.98 & 3.21 & 3.00 & 3.09 & 3.20 \\
RCP 4.5 50\% & 1.70 & 2.45 & 2.56 & 2.40 & 2.62 & 2.71 \\
RCP 4.5 25\% & 1.40 & 1.76 & 1.70 & 2.10 & 2.12 & 2.17 \\
\hline RCP 8.5 75\% & 4.50 & 6.07 & 5.87 & 5.60 & 6.40 & 6.74 \\
RCP 8.5 50\% & 3.90 & 5.07 & 5.09 & 4.90 & 5.49 & 5.37 \\
RCP 8.5 25\% & 3.40 & 4.02 & 4.09 & 4.30 & 4.53 & 4.41 \\
\hline
\end{tabular}

Table 2: Same as Table 1 but for changes $\left(\Delta R_{20}\right)$ of annual maximum daily precipitation, and for CMIP5 median waiting times of 20 -year return level $\left(R_{20}\right)$ relative to 1995 , denoted by $\mathrm{WT}\left(\mathrm{R}_{20(1995)}\right)$.

\begin{tabular}{c|ccc|ccc}
\hline & \multicolumn{3}{|c|}{$\Delta \mathrm{R}_{20}(\%)$} & \multicolumn{3}{c}{$\mathrm{WT}\left(\mathrm{R}_{20(1995)}\right)$ (years) } \\
Quartiles & Globe & East Asia & Korea & Globe & East Asia & Korea \\
\hline RCP 2.6 75\% & 8.70 & 8.48 & 11.17 & 15.30 & 27.92 & 67.97 \\
RCP 2.6 50\% & 6.20 & 6.27 & 5.65 & 14.70 & 23.12 & 22.20 \\
RCP 2.6 25\% & 4.30 & 4.14 & 0.74 & 13.70 & 19.18 & 17.53 \\
\hline RCP 4.5 75\% & 13.00 & 16.49 & 18.01 & 12.90 & 14.86 & 18.42 \\
RCP 4.5 50\% & 10.00 & 14.88 & 14.88 & 11.00 & 13.40 & 12.97 \\
RCP 4.5 25\% & 8.00 & 11.83 & 10.96 & 10.40 & 11.02 & 9.92 \\
\hline RCP 8.5 75\% & 36.00 & 37.90 & 41.16 & 7.60 & 7.06 & 7.51 \\
RCP 8.5 50\% & 25.00 & 31.37 & 29.27 & 6.60 & 6.39 & 5.36 \\
RCP 8.5 25\% & 19.00 & 22.16 & 25.92 & 5.80 & 5.56 & 4.62 \\
\hline
\end{tabular}


$\Delta T X 20$

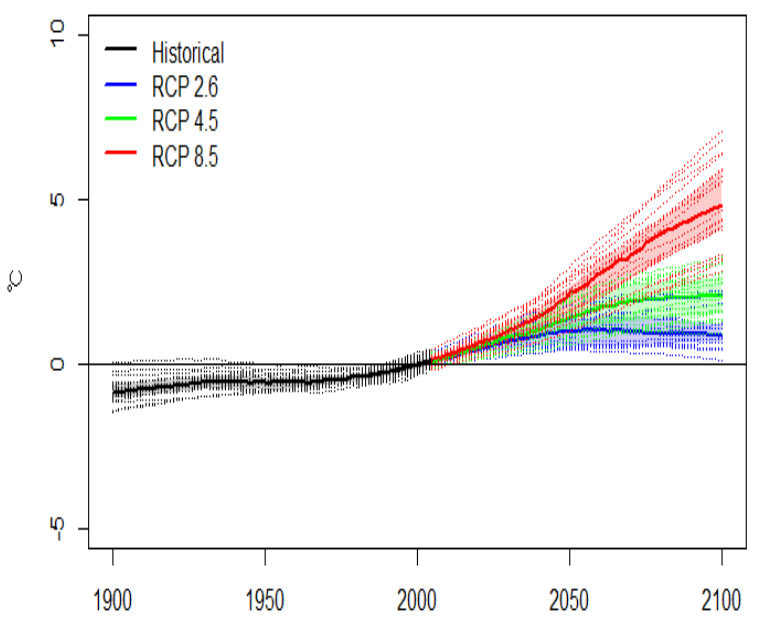

$\Delta T$ T20_Korea

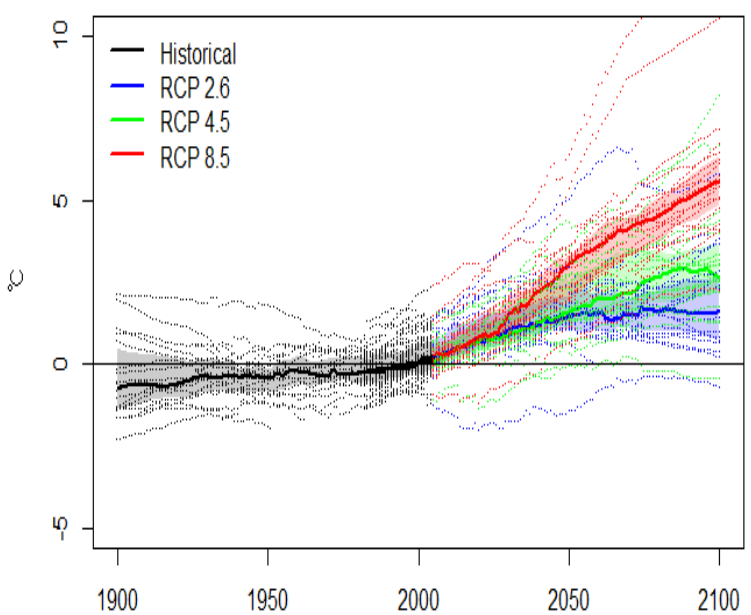

Return period of $T X(y r s)$

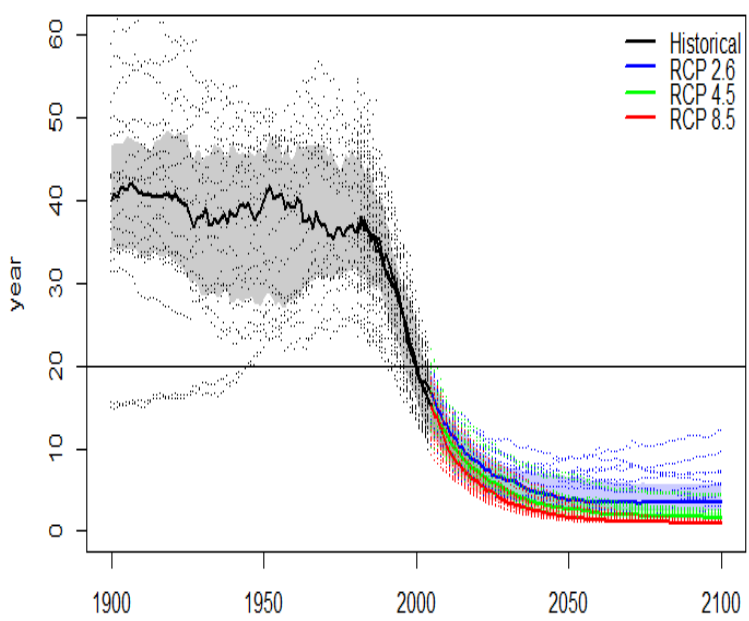

Return period of TX(yrs) Korea

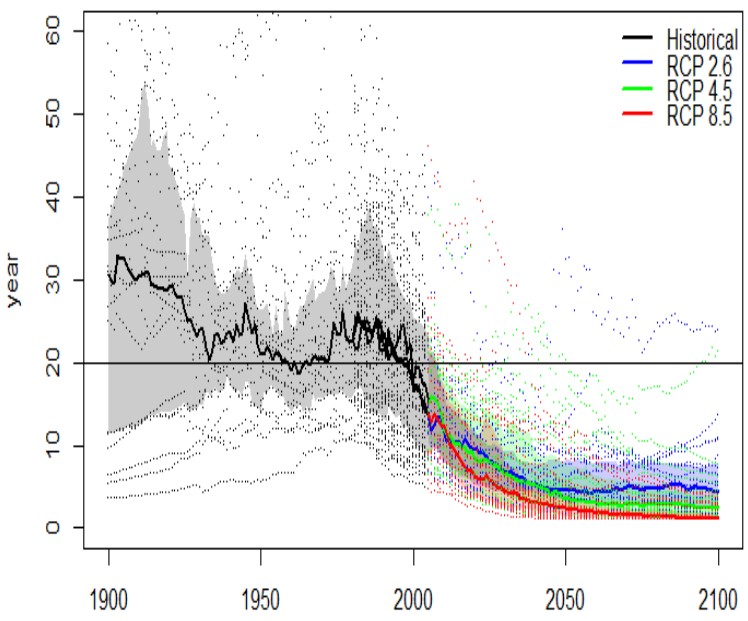

Figure 3: Left panels: The CMIP5 ensemble change $\left(\Delta \mathrm{TX}_{20}\right)$ in 20-year return levels of the annual warmest daily temperature $T X_{20}\left({ }^{\circ} \mathrm{C}\right)$ averaged over East Asia and Korea relative to 1986-2005 in the historical, RCP2.6, RCP4.5, and RCP8.5 experiments. Right panels: The regional medians of the waiting times corresponding to $T X_{20}$ based on the year 1995 are displayed. Thick solid lines and shading are the ensemble means and inter-quartile range (75\% $-25 \%)$ respectively. Dotted lines indicate individual model simulations. 
$\Delta$ TN20

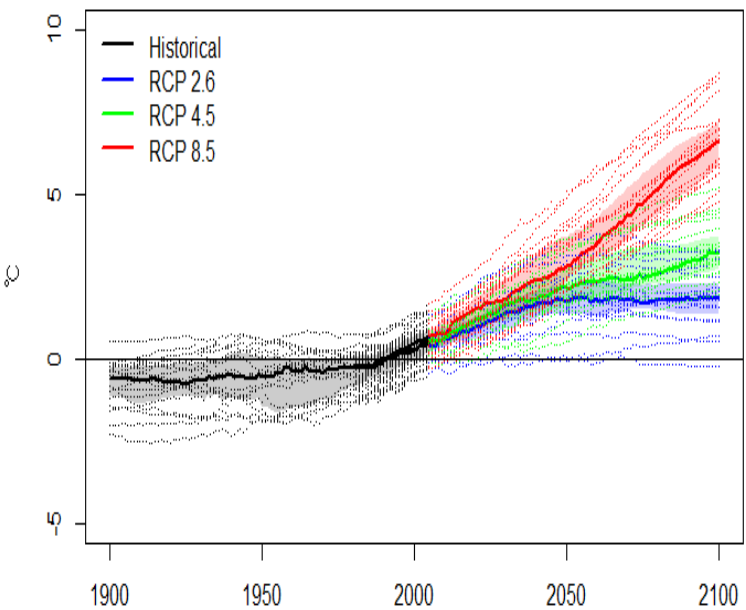

$\Delta T$ TN20_Korea

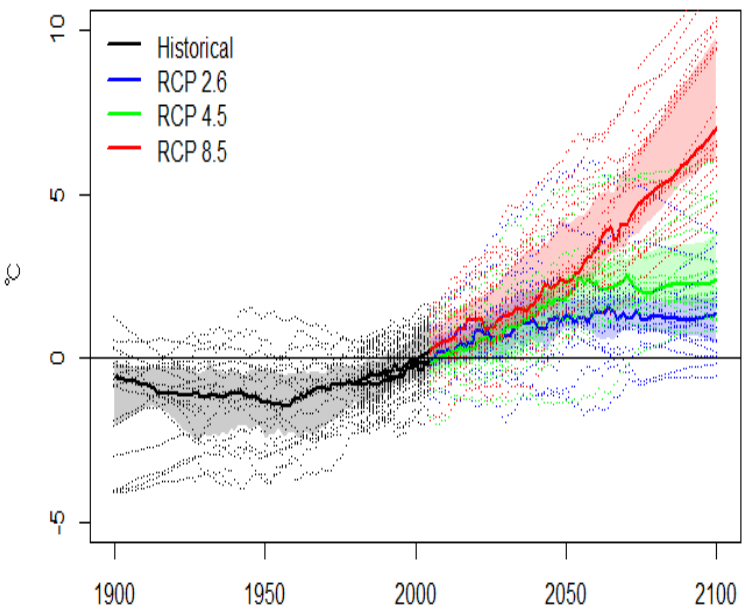

Return period of TN(yrs)

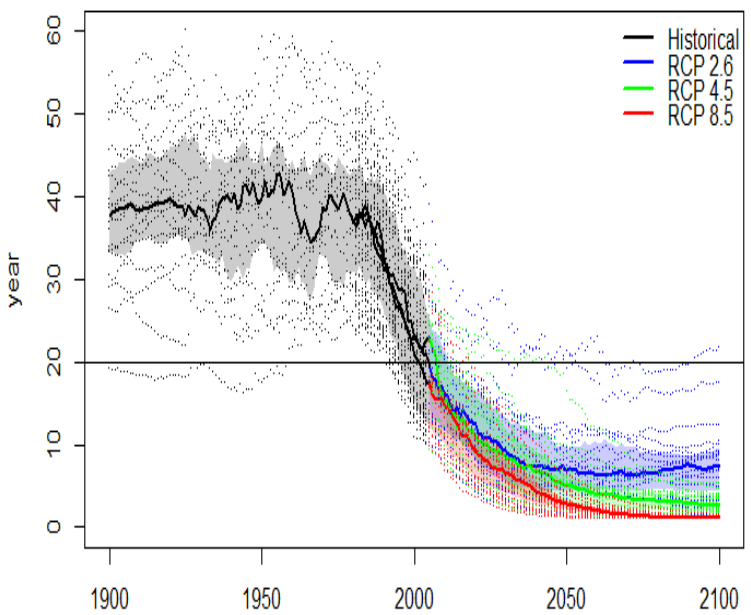

Return period of TN(yrs) Korea

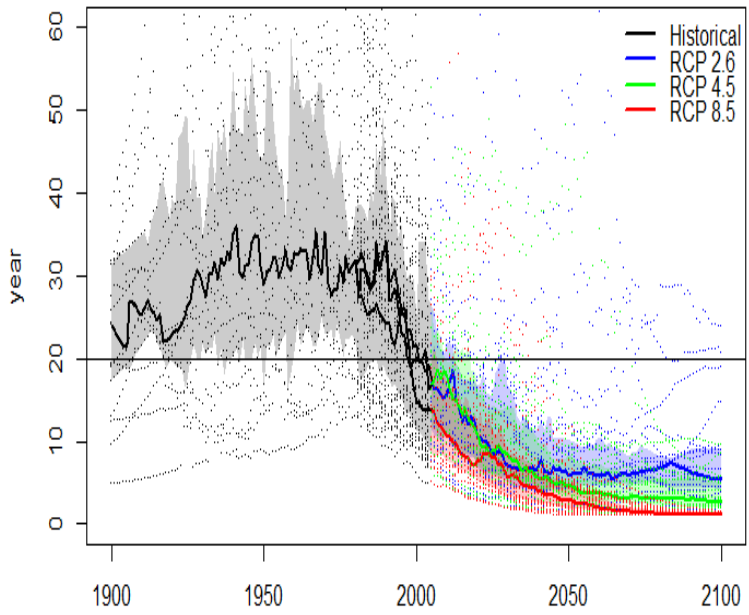

Figure 4: Same as Figure 3 but for the change $\left(\Delta \mathrm{TN}_{20}\right)$ of the annual coldest temperature $T N_{20}$. 
higher than that in high temperatures globally. The AR5 predicted that this trend is continued in the future with less variance compared with the past and appears more distinctly for the local scale than globally. As an example, the biggest (second) rises in temperature extremes are found in Korea (EA) in this comparison.

Figures 3 and 4 show the changes of $T X_{20}$ and $T N_{20}$ from the CMIP 5 ensembles across EA and Korea in 1900-2100, respectively. For both $T X_{20}$ and $T N_{20}$, the decrease rates in waiting times in EA are faster than the corresponding values in Korea. The regional medians of the waiting times corresponding to 20-year events based on the year 1995 are displayed in the right panels of Figures 3 and 4. The waiting times for the coldest temperatures over EA are 8, 2, and 1 years, for RCP 2.6, RCP 4.5, RCP8.5 (3, 1, and 1 years for the warmest temperatures), respectively. Similarly, the waiting times of $T N$ over Korea are 5, 2, and 1 years for the three scenarios $(4,2$, and 1 years for $T X)$, respectively.

Figure S6 shows the future relative changes of the 20-year return levels for 2081-2100 relative to 1986-2005 from the CMIP5 ensemble in the three RCP scenarios. The zonally averaged increases of temperature extremes projected for 2081-2100 in all three RCP scenarios are approximately from 1.5 to $6.2^{\circ} \mathrm{C}$. The biggest increase in temperature extremes is found in RCP8.5. Figure S7 displays the box-and-whisker plots of the future changes relative to 1986-2005 in $\mathrm{TX}_{20}$ and $\mathrm{TN}_{20}$ as simulated by the CMIP5 models in future periods. The future rising trends in temperature extremes across EA and across Korea are similar.

\subsection{Changes in rainfall extremes}

Some authors including Ho et al (2011), Park et al (2011), Zhou et al (2014), Seo et al (2016), Kim et al (2019), and Lee et al (2020) have reported future increases in the heaviest rainfall across EA or across Korea. They projected that the annual maximum precipitation will vary in intensity with shortened waiting times.

Figure 5 shows the CMIP5 ensemble change in the 20-year return levels of the annual largest rainfall, denoted by $\Delta R_{20}(\%)$, averaged over EA and Korea relative to 1986-2005. The rising rate in return levels and dropping rate in waiting times in EA are similar to those in Korea. The $\Delta R_{20}$ increases by $7 \%, 15 \%$, and $35 \%$ up to 2100 for EA and $6 \%, 17 \%$, and $37 \%$ for Korea for RCP2.6, RCP4.5, and RCP8.5, respectively. The $\Delta R_{20}$ over EA and Korea are higher than the global figures reported in K13. The result in Korea is comparable with those by Lee et al (2020), in which they reported $23 \%$ and $45 \% \Delta R_{20}$ increases for RCP 4.5 and RCP8.5 respectively, relative to the observations in 1971-2005.

The 20-year waiting times decrease to 14, 9, and 5 years across EA, and 13, 10, and 4 years for Korea, for RCP2.6, RCP4.5, and RCP8.5, respectively, by the end of the 21st century.

These decreases are faster than the global decreases provided by K13. Korea shows similar 
$\Delta R 20(\%)$
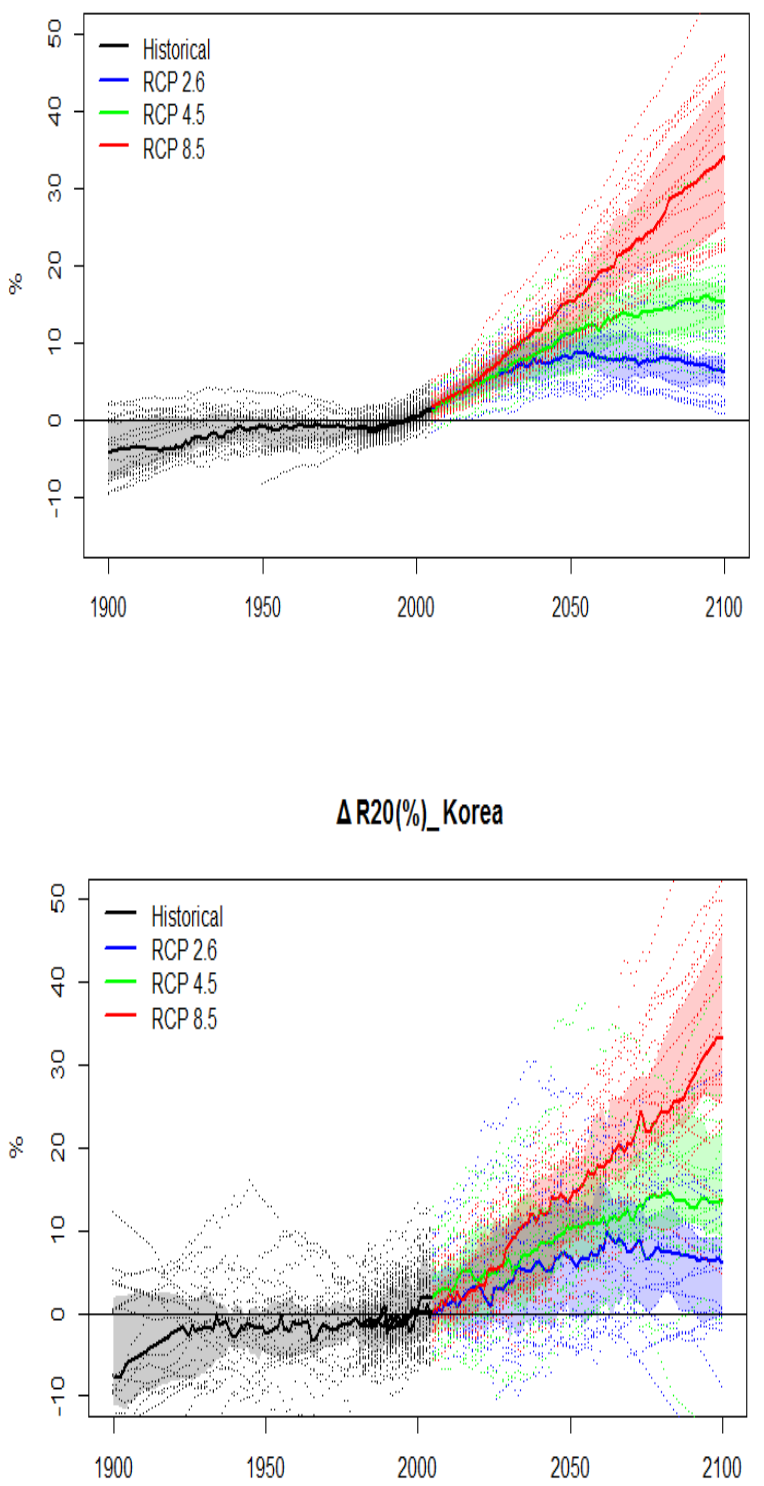

Return period of R20(yrs)

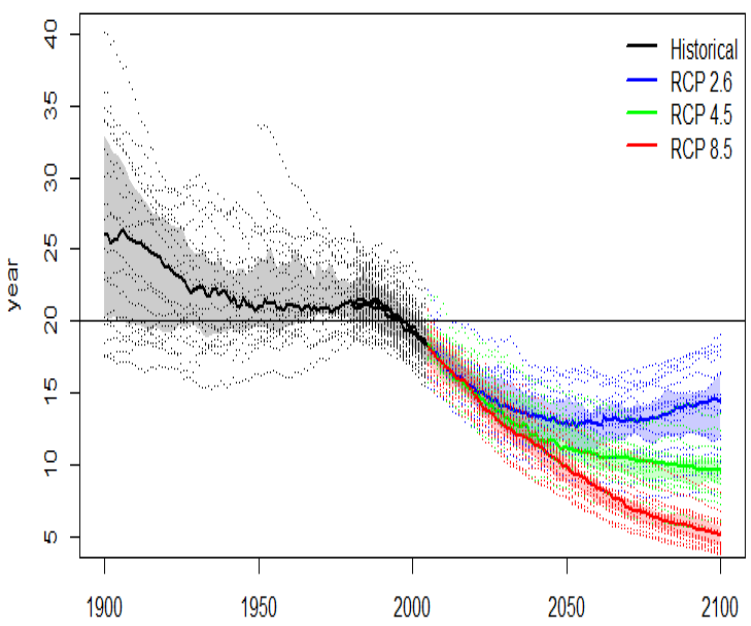

Return period of R20(1995), yrs_Korea

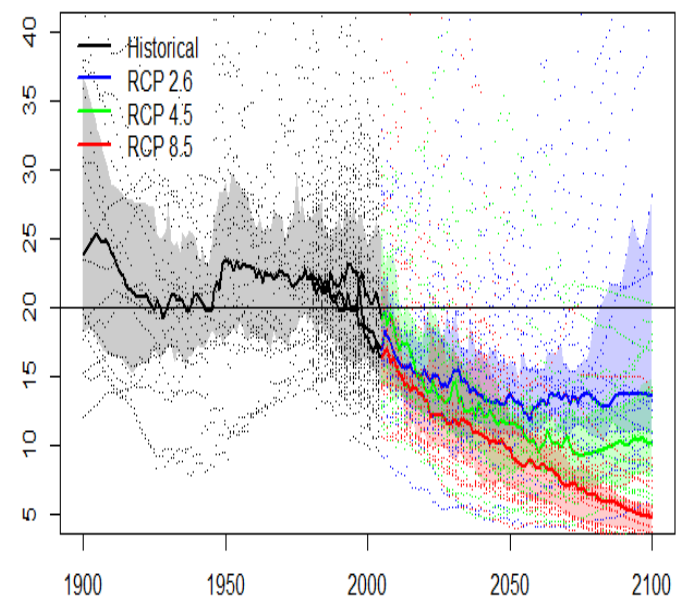

Figure 5: Same as Figure 3 but for changes $\left(\Delta R_{20}, \%\right)$ of 20 -year return levels, and for the 20-year waiting times of the annual maximum precipitation $R_{20}$. 
$\mathrm{r} 26, \Delta \mathrm{R} 20, \%, 2016-2035,8.611 \%$

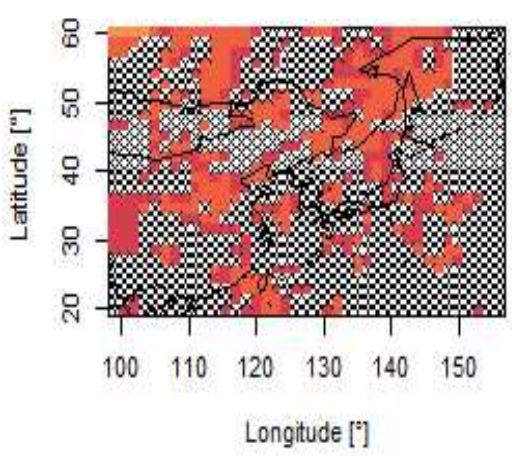

I $45, \Delta R 20, \%, 2016-2035,7.242 \%$

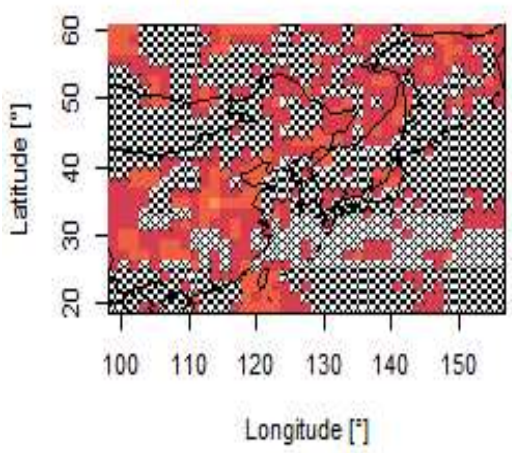

$\mathrm{r} 85, \Delta \mathrm{R} 20, \%, 2016-2035,8.101 \%$

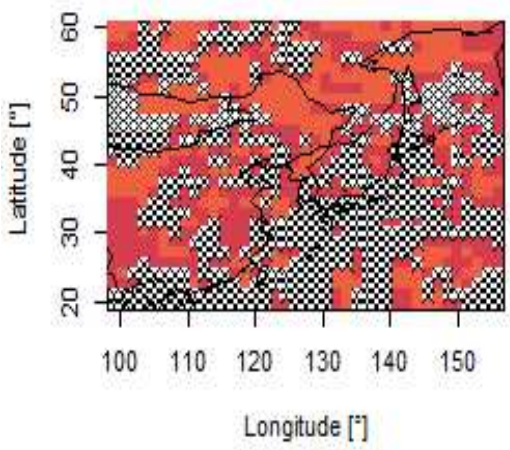

r26, $\Delta \mathrm{R} 20, \%, 2046-2065,10.344 \%$

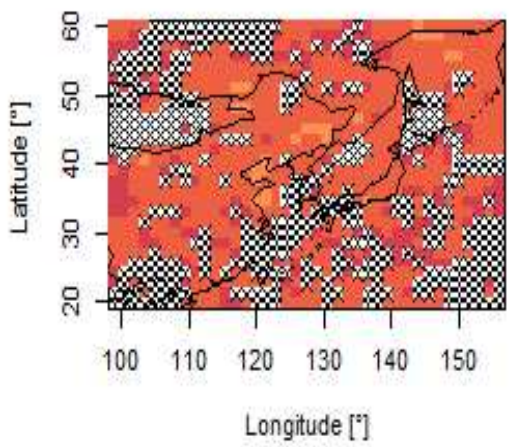

I45, $\Delta$ R20, \%, 2046-2065, $11.915 \%$

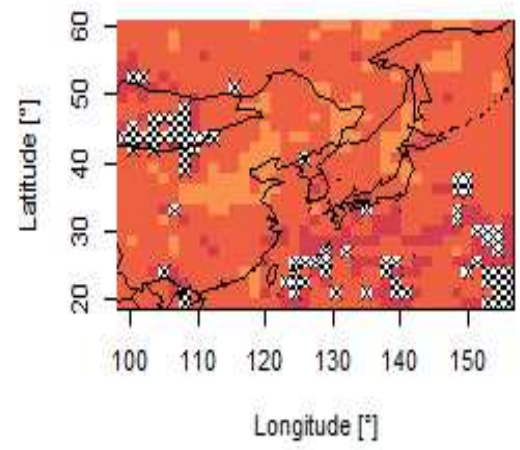

r85, $\Delta$ R20, \%, 2046-2065, 16.543\%

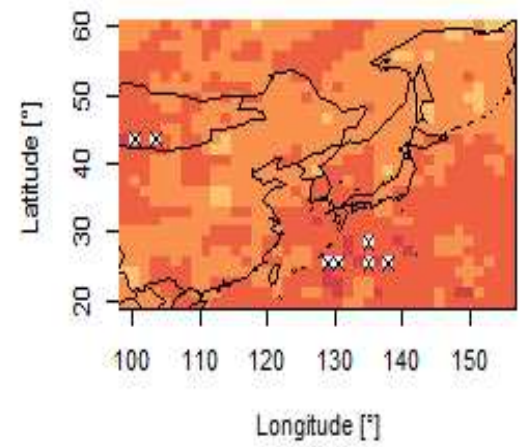

r26, $\Delta \mathrm{R} 20, \%, 2081-2100,10.059 \%$

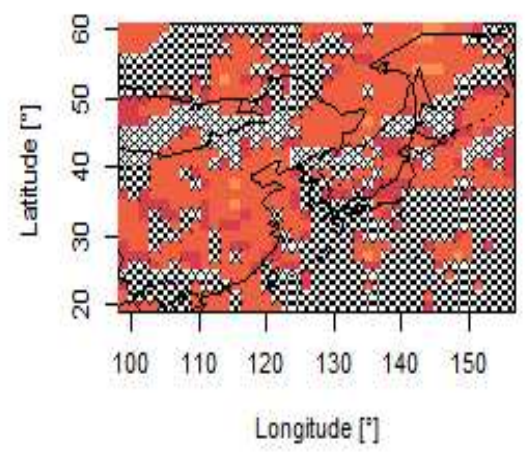

r $45, \Delta \mathrm{R} 20, \%, 2081-2100,15.343 \%$

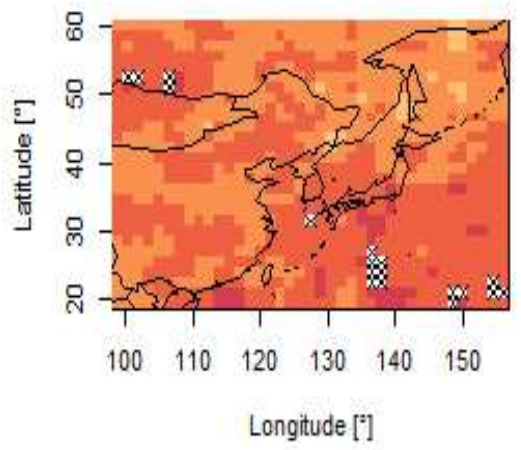

$\mathrm{r} 85, \Delta \mathrm{R} 20, \%, 2081-2100,31.793 \%$

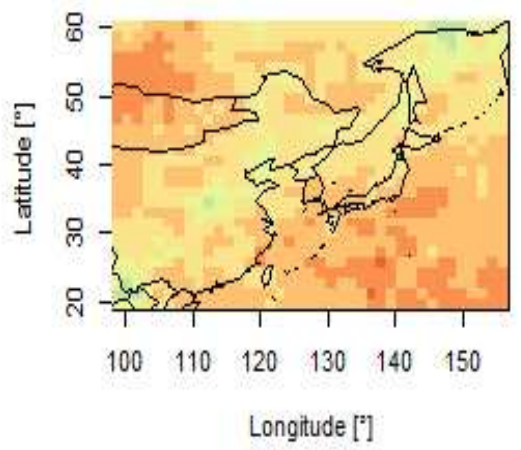

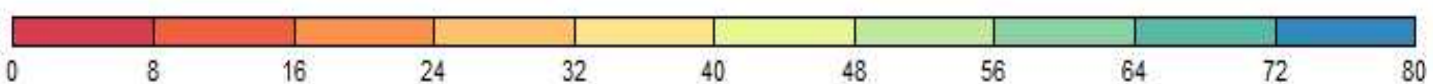

Figure 6: CMIP5 median relative change (\%)1 1 th 20 -year return levels of annual largest daily rainfall simulated in 2016-2035 (left column), 2046-2065 (middle column), and 2081-2100 (right column) relative to 1986-2005 in RCP2.6 (top panels), RCP4.5 (middle panels), and RCP8.5 (bottom panels). Changes that are not statistically significant at the $5 \%$ level are marked by cross-hatching. 
sign of the projected changes with enhanced trend. The 20-year waiting times for Korea are comparable with the results by Seo et al (2015) and by Lee et al (2020). Seo et al (2015) obtained that the values decrease to 5 and 4 years relative to historical data (11 and 8 years relative to observations) for RCP4.5 and RCP8.5, respectively. Lee et al (2020) reported these values be 10 and 5 years relative to the observations in 1971-2005, which is similar to the result of this study.

Table 2 summarizes changes (\%) in the CMIP5 median and quartiles (25\% and $75 \%$ ) relative to $1986-2005$ in zonally averaged $R_{20}$ across the globe, EA, and Korea in 2081-2100. The corresponding multimodel median waiting times of $R_{20}(1995)$, denoted by WT $\left(\mathrm{R}_{20}(1995)\right)$, are also listed. Similar to temperature extremes, the biggest changes in $R_{20}$ by the end of the 21st century are found in RCP8.5.

Figure 6 is a collection of contour maps showing the spatial change (\%) of $R_{20}$, denoted by $\Delta R_{20}$, across EA for the three future periods from the CMIP5 ensemble relative to 19862005. The $\Delta \mathrm{R}_{20}$ over EA are about $7-9 \%$ for $2016-2035,10-17 \%$ for $2046-2065$, and $8-32$ $\%$ for 2081-2100. The differences in the scenarios are small in 2016-2035. Changes that are not statistically significant at the $5 \%$ level are marked by cross-hatching. We can see more significant changes for the far right and for the far bottom maps. This is because the climatic effect of the different emission scenarios appear distinctly after the mid-21st century, as mentioned in the IPCC AR5 (2013).

Figure S8 shows the variations of the annual 'mean' precipitation for the future three periods from the CMIP5 ensemble relative to the period 1986-2005. Similar to the changes in $\mathrm{R}_{20}$, the biggest increases are found in RCP8.5. The mean and the maximum precipitation have different increasing patterns. The former rises as latitude increases whereas the latter increases across the coastal areas in EA, as seen in Figures 5 and 6 . It is notable that the increases of $\Delta R_{20}$ are twice as fast as those of the annual mean rainfall for the future. For example, $\Delta \mathrm{R}_{20}$ up to year 2100 in RCP8.5 is $32 \%$ while the change of the annual mean rainfall is $16 \%$ for the same period and RCP. This phenomenon is also confirmed in Figure 7 of the next subsection.

Figure S9 shows the box-and-whisker plots of relative changes (\%) in the regionally averaged $\Delta \mathrm{R}_{20}$ and in regional medians with a notation $\mathrm{RC}\left(\mathrm{R}_{20}(1995)\right)$. In both EA and Korea, the biggest $\Delta \mathrm{R}_{20}$ and lowest waiting time are found in 2081-2100 in RCP8.5.

\subsection{Changes in rainfall extremes by the rise of temperature}

There is a dispute that change in extreme rainfall may accompany a change in temperature in view of the Clausius-Clapeyron $(\mathrm{C}-\mathrm{C})$ relation that predicts an increase in moisture availability of about $6-7 \% /{ }^{\circ} \mathrm{C}$ (e.g., Boer 1993; Allen and Ingram 2002; Westra et al 2013). It is a big 
concern that the extreme rainfall of a sub-daily or hourly time scale tends to be increasing (up to a doubled $\mathrm{C}-\mathrm{C}$ rate) with the temperature change, which is known as a super C-C scaling (Lenderink and van Meigjaard 2008; Berg et al 2013; Park and Min 2017). The super $\mathrm{C}-\mathrm{C}$ scaling has been observed in many regions including Europe, North America, Hong Kong, Japan, and Korea.

Figure 7 and Figure 8 display the percentage changes in $R_{20}$ averaged across EA and across the Korean peninsula, respectively, as a function of the regional annual mean temperature variation as simulated by the CMIP5 models in 2046-2065 and 2081-2100 in the three emission scenarios. We did this work across EA and across Korea by following the linear regression method as in K13. The regression fit is marked by the dashed line in Figure 7 with the slope of about $5.5 \% /{ }^{\circ} \mathrm{C}$, which is lower than that $\left(5.8 \% /{ }^{\circ} \mathrm{C}\right)$ for the globe reported in K13. The value is $7.38 \% /{ }^{\circ} \mathrm{C}$ for Korea, which is much higher than that for EA and globally. In Figures 7 and 8, the increasing patterns in EA are similar to the global patterns. These patterns appear more distinctly in Korea as a local scale.

The regression fitting over EA for annual precipitation on annual mean temperature indicates a $1.79 \% /{ }^{\circ} \mathrm{C}$ rise, which is similar to that $\left(1.8 \% /{ }^{\circ} \mathrm{C}\right)$ for the globe. This result is consistent with IPCC AR5 (2013) in which the increase of annual rainfall is only about $2 \%$ because of the weak atmospheric circulation even though the increase in moisture availability is about $7 \%$. This study illustrates that in EA, the change effect for rainfall extremes $\left(R_{20}\right)$ according to the increase of temperature is more severe than that for annual rainfall. The value for Korea is $2.57 \% /{ }^{\circ} \mathrm{C}$ as seen in Figure 8 .

The upper right panel in Figure 7 is a histogram of the hydrological sensitivities, with a notation $\Delta \mathrm{R}_{20} \% / \Delta \mathrm{T},{ }^{\circ} \mathrm{C}$, of the CMIP5 ensemble for the annual largest rainfall across $\mathrm{EA}$. This figure indicates considerable inter-model uncertainty in these sensitivity statistics, where the bulk of model values are in the $4-10 \% /{ }^{\circ} \mathrm{C}$ range. By comparison, the lower diagram in Figure 7 shows similar statistics for the annual mean rainfall, where most of the model values are in the $1-4 \% /{ }^{\circ} \mathrm{C}$ range.

\section{Summary}

We studied the performance of the CMIP5 models in simulating annual extremes of surface temperature and daily rainfall, and their projected changes for three scenarios, RCP2.6, RCP4.5, and RCP8.5. Our findings across EA and Korea and global comparisons are summarized as follows.

1. The warm and cold temperature extremes of 1986-2005 over EA are observed as lower than the global average. The 20-year return level of the annual warm and cold extremes 

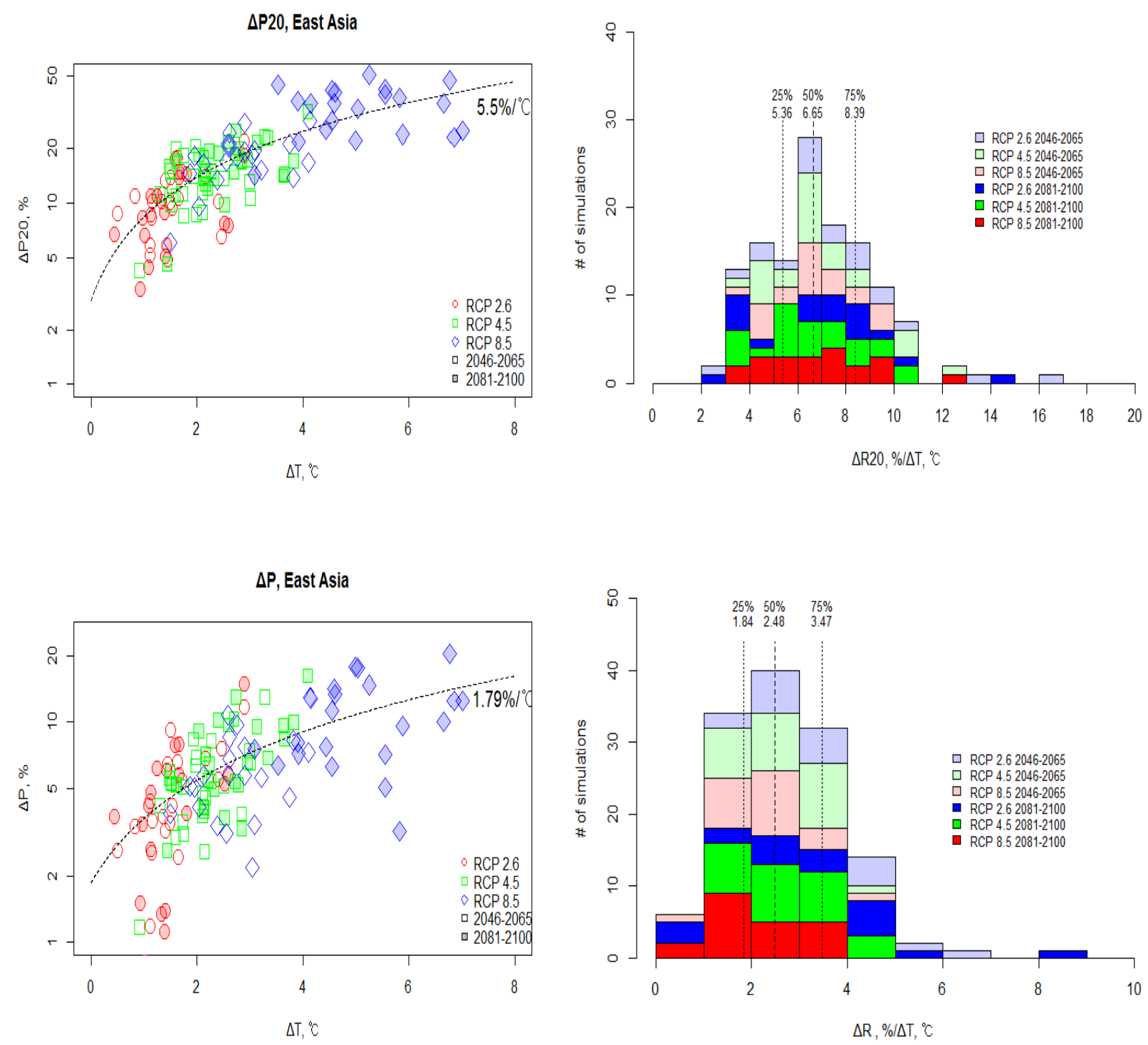

Figure 7: Top left panel: Relative changes (\%) in averaged 20-year return levels of annual largest daily rainfall $\left(\Delta R_{20}\right)$ over East Asia plotted on a log scale as a function of averaged changes in annual mean surface temperature $\left(\Delta \overline{\mathrm{T}},{ }^{\circ} \mathrm{C}\right)$ simulated by the CMIP5 models in the three scenarios in 2046-2065 and 2081-2100. The linear regression fit is marked by the dashed line. Top right panel: Histogram of maximum precipitation sensitivities $\left(\Delta \mathrm{R}_{20} / \Delta \overline{\mathrm{T}}\right.$, $\left.{ }^{\circ} \mathrm{C}\right)$ over East Asia. The median value and quartiles $(25 \%, 75 \%)$ are indicated by the vertical dashed and dotted lines respectively. Bottom panels: same as the above but for changes in annual mean rainfall $(\Delta \bar{R})$ instead of $\Delta \mathrm{R}_{20}$. 
$\Delta R 20$, Korea

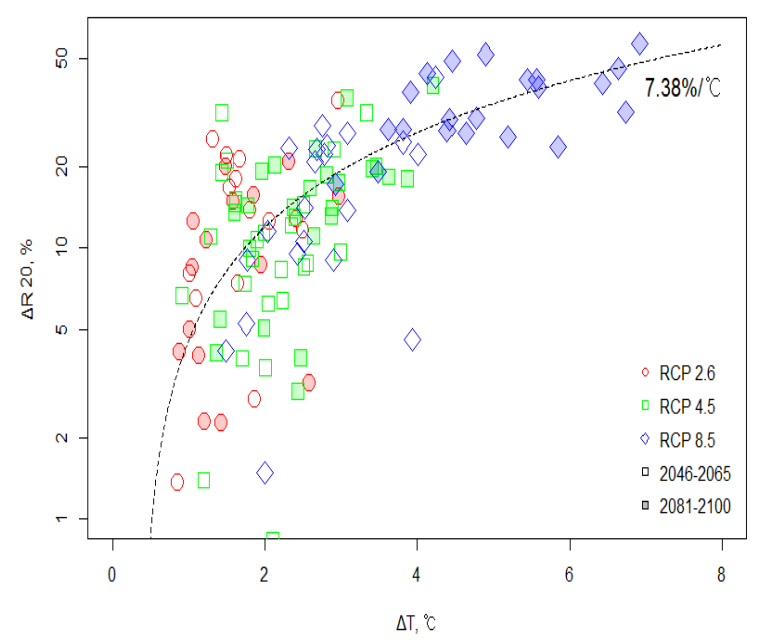

$\Delta T,{ }^{\circ} \mathrm{C}$

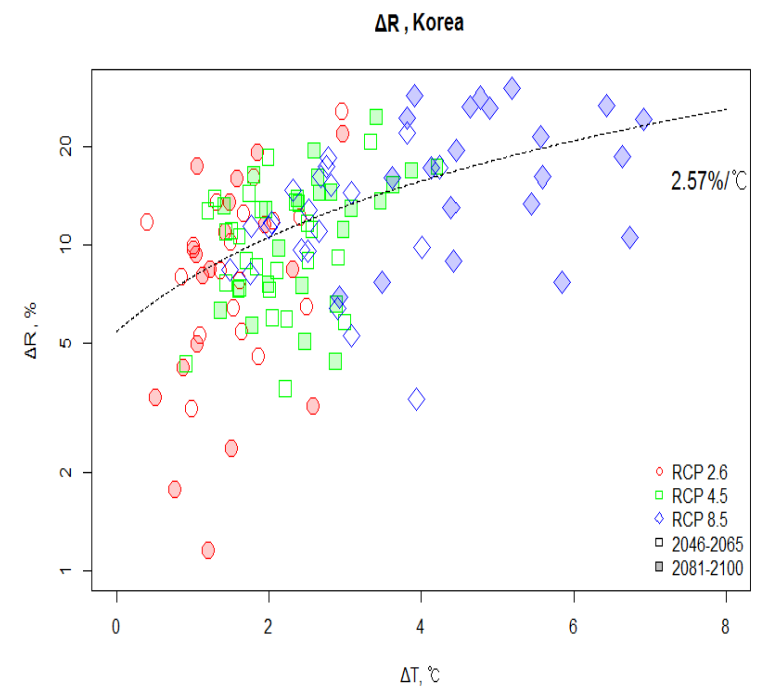

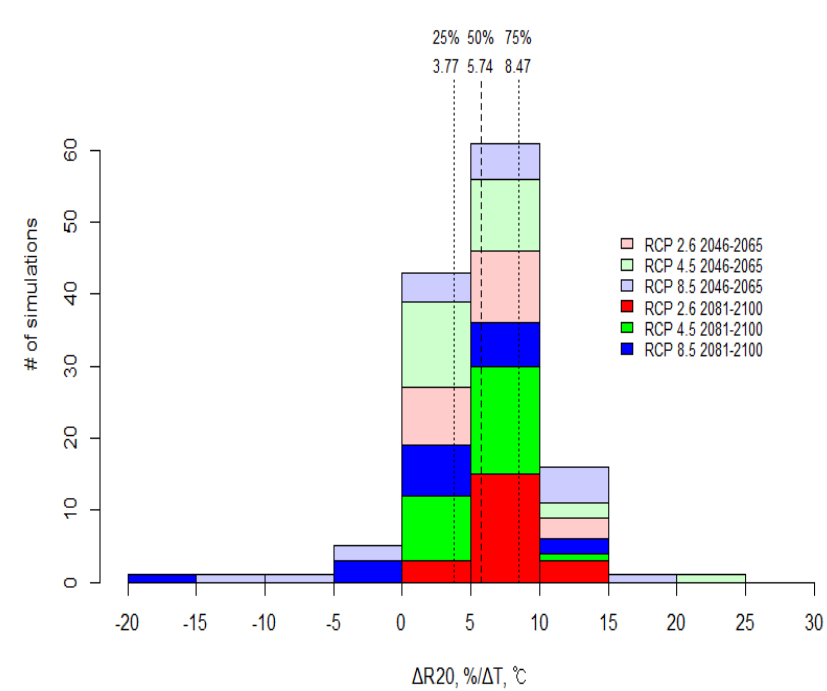

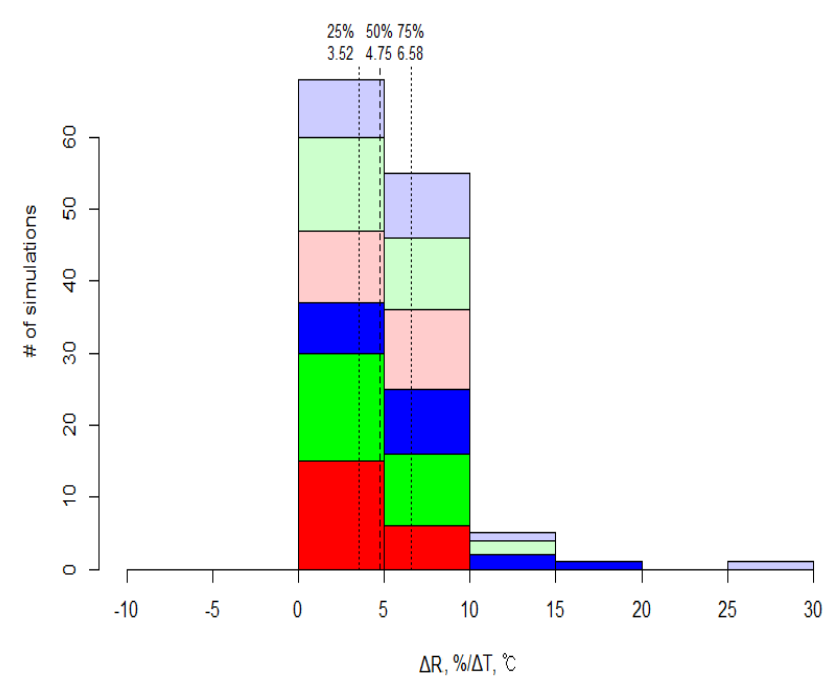

Figure 8: Same as Figure 7 but for the Korean peninsula. 
from the reanalyzed datasets (ERA-I and NCEP2) across EA are within the range of the CMIP5 median estimate. The increasing trends in warm and cold extremes across EA are greater than the global trends.

2. Cold extremes across EA and Korea get warmer faster than warm extremes, which is the same as the global figures reported in K13. The CMIP5 median warming of cold extremes over the EA by the end of the 21 st century are $1.9^{\circ} \mathrm{C}, 3.2^{\circ} \mathrm{C}$, and $6.7^{\circ} \mathrm{C}$ in the $\mathrm{RCP} 2.6$, $\mathrm{RCP} 4.5$, and RCP8.5 experiments, respectively, as compared with the corresponding increases of $0.9^{\circ} \mathrm{C}, 2.0^{\circ} \mathrm{C}$, and $4.8^{\circ} \mathrm{C}$ for warm extremes. The rise in cold extremes over Korea are $1.3^{\circ} \mathrm{C}, 2.4^{\circ} \mathrm{C}$, and $7.0^{\circ} \mathrm{C}$ in the three scenarios, respectively, as compared with the corresponding increases of $1.6^{\circ} \mathrm{C}, 2.6^{\circ} \mathrm{C}$, and $5.5^{\circ} \mathrm{C}$ for warm extremes.

3. Relative increases (\%) in the intensity of rainfall extremes over EA and Korea generally exceed the global figures reported in Kharin et al.(2013). The regionally averaged $R_{20}$ increases in the CMIP5 ensemble over EA up to year 2100 are about $7 \%$ in the RCP2.6, $15 \%$ in the RCP 4.5 , and $35 \%$ in the RCP 8.5 experiment. This is 1.5 to 2 times faster than the corresponding results of global multimodel changes.

4. Waiting times for 20-year extreme rainfall events based on 1986-2005 across EA are projected to shorten to about 14,9 , and 5 years $(13,10$, and 4 years over Korea) by the end of the 21st century in the RCP2.6, RCP4.5, and RCP8.5 scenarios, respectively.

5. Overall, 20-year return levels of temperature and rainfall extremes in the CMIP5 ensemble over EA and Korea are larger than those for the globe. Warm and cold extremes over EA show a higher rapid warming rate than the globe. Changes in the 20-year rainfall events in EA and Korea are also faster than the global changes.

6. The CMIP5 multimodel estimate of the sensitivity in extreme rainfall $\left(R_{20}\right)$ to the annual mean temperature variation across $\mathrm{EA}$ is about $5.5 \% /{ }^{\circ} \mathrm{C}$, which is lower than the global estimate $\left(5.8 \% /{ }^{\circ} \mathrm{C}\right)$ reported in $\mathrm{K} 13$. This value for the Korean peninsula is $7.38 \% /{ }^{\circ} \mathrm{C}$.

\section{Discussion}

It is generally accepted that increasing greenhouse gases induce atmospheric temperature warming, which results in rising equivalent potential temperature and specific humidity according to the Clausius-Clapeyron relationship (Ruckstuhl et al 2007). The increase in atmospheric water vapor is the main factor in generating convective instability. In view of this insight, Kim et al (2019) obtained an indication that increasing extreme precipitation over South Korea in the past and in the future under RCP scenarios is more related to a change in convective 
instability rather than synoptic conditions. We expect this explanation to be extended to the EA region but we may need more evidence to do so.

Another plausible explanation for the increase of maximum precipitation in the future is a connection to the high possibility of the rise of strong typhoons in both frequency and strength. Some regions including south-western Japan, southern Korea, and south-eastern China are in the typhoon high-impact range. Park et al (2016) evaluated multiple regional climate models (RCMs) for summer climate extremes over EA. Such multiple RCMs accompanied by multiple general circulation models (GCMs) must be very useful in understanding the future climate over EA. Assessing changes in climate extremes over EA by combining and comparing these multiple RCMs and GCMs is a future research topic.

A reanalysis data APHRODITE (Asian Precipitation Highly-Resolved Observational Data Integration Towards Evaluation; Yatagai et al 2012) might be a better choice for Asian domain. However it is not employed in this study because we concentrated to compare results over EA to the global values which were obtained by Kharin et al (2013) without APHRODITE.

The ensemble methods applied in this study are the simple (or equally weighted) average or the median of the statistics obtained from multimodels. Many studies including Suh et al (2012), Zhu et al (2013), Niu et al (2018), and Shin et al (2019b), however, applied the unequally weighted average methods. These weighted average methods, including the Bayesian model averaging, combine the forecast distribution of different models and build a weighted predictive distribution out of multiple models. The weight of each model is calculated by comparing the reanalysis data and the historical data from a simulation model. If there are some differences in the reliability or fidelity of models, these weighted average techniques are worthy of being employed as ensemble forecasts.

There is high probability that the numerical model is biased systematically. To solve this problem, one can apply the bias correction technique which constructs a mapping that matches the observations and the historical data well. Some studies, including Piani et al (2010), Sangelantoni et al (2019), Shin et al (2019a), and Lee et al (2020), applied the statistical bias correction methods to the output of models, in which the obtained mapping for the past was applied to the simulation data for future periods. Such application may be valid under the assumption that the relationship between observations and historical simulation is kept very similar in the future. This approach may improve the model output and thus, the ensemble prediction may be more realistic and reliable.

\section{Acknowledgement}

The authors would like to thank the reviewers, the associate editor, and the editor for helpful suggestions, which have greatly improved the presentation of this paper. We acknowledge the World Climate 
Research Programme Working Group on Coupled Modelling, which is responsible for CMIP, and we thank the climate modelling groups for producing and making available their model output. For CMIP5, the U.S. Department of Energy Program for Climate Model Diagnosis and Intercomparison provides coordinating support and led development of software infrastructure in partnership with the Global Organization for Earth System Science Portals. This work was funded by the Korea Meteorological Administration Research and Development Program under Grant KMI2018-03414, and supported by the National Research Foundation of Korea (NRF) grant funded by the Korea government (MSIP) (No.2016R1A2B4014518).

\section{References}

AghaKouchak A, Easterling D, Hsu K, Schbert S, and Sorooshian S (ed) (2013) Extremes in a Changing Climate: Detection, Analysis and Uncertainty. Springer.

Allen MR, Ingram WJ (2002) Constraints on future changes in climate and the hydrologic cycle. Nature 419:224-232.

Alexander LV, Zhang X, Peterson TC, Caesar J et al (2006) Global observed changes in daily climate extremes of temperature and precipitation. Jour Geophys Res 111, D05109

Alexander LV (2016) Global observed long-term changes in temperature and precipitation extremes: a review of progress and limitations in IPCC assessments and beyond. Weather and Climate Extremes 11:4-16.

Berg P, Moseley C, Haerter JO (2013) Strong increase in convective precipitation in response to higher temperatures. Nat Geosci 6:181-185.

Boer GJ (1993) Climate change and the regulation of the surface moisture and energy budgets. Clim Dynamics 8:225-239.

Dee DP, Uppala SM, Simmons AJ et al (2011) The ERA-Interim reanalysis: configuration and performance of the data assimilation system. Quart J R Meteorol Soc 137:553-597.

Fischer AM, Weigel AP, Buser CM, Knutti R et al (2012) Climate change projections for Switzerland based on a Bayesian multi-model approach. Intern J Climatol 32:2348-2371.

Flower HJ, Ekstrom M (2009) Multi-model ensemble estimates of climate change impacts on UK seasonal precipitation extremes. Intern J Climatol 29(3):385-416.

Freychet N, Hsu H, Chou C, Wu C (2015) Asian summer monsoon in CMIP5 projections: a link between the change in extreme precipitation and monsoon dynamics. J Clim doi:10.1175/JCLI-D-1400449.1

Freychet N, Hsu HH, Wu CH (2016) Extreme precipitation events over East Asia: Evaluating the CMIP5 model. In: Coleman JSM (ed) Atmosperic Hazards - Case studies in modeling, communication, and societal impacts, IntechOpen, http://dx.doi.org/10.5772/62996

Ho C-H, Park T-W, Jun S-Y et al (2011) A projection of extreme climate events in the 21st century over East Asia using the community climate system model 3. Asia Pac J Atmos Sci 47:329-344

Hosking JRM (1990) L-moments: analysis and estimation of distributions using linear combinations of order statistics. J Roy Statist Soc 52:105-124.

IPCC AR5 (2013) Fifth Assessment Report (AR5) by Intergovernmental Panel on Climate Change (IPCC). Available at https://www.ipcc.ch/report/ar5/ 
Jiang R, Xie J, Zhao Y, He H et al (2017) Spatiotemporal variability of extreme precipitation in Shaanxi province under climate change. Theor Appl Climatol 130:831-845.

Kharin VV, Zwiers FW, Zhang X, Hegerl GC (2007) Changes in temperature and precipitation extremes in the IPCC ensemble of global coupled model simulations. J Climate 20:1419-1444.

Kharin VV, Zwiers FW, Zhang X, Wehner M (2013) Changes in temperature and precipitation extremes in the CMIP5 ensemble. Clim Change 119:345-357.

Kim G, Cha D-H, Park C, Lee G, Jin C-S et al (2019). Future changes in extreme precipitation indices over Korea. Int J Climatol 38(6):862-874 DOI:10.1002/joc.5414

Kitoh A, Endo H, Kumar KK, Cavalcanti IFA et al (2013) Monsoon in a changing world: A reginal perspective in a global context. Jour Geophy Res:Atmos 118:3053-3065.

Kwon SH, Kim J, Boo KO, Shim S et al (2019) Performance-based projection of the climate change effects on precipitation extremes in East Asia using two metrics. Intern J Climatol 39(4):2324-2335.

Lee Y, Shin YG, Park JS, Boo KO (2020) Future projections and uncertainty assessment of precipitation extremes in the Korean peninsula from the CMIP5 ensemble. Atmos Sci Lett e954. https://doi.org/10.1002/asl.954

Lenderink G, van Meijgaard E (2008) Increase in hourly precipitation extremes beyond expectations from temperature changes. Nature Geosci 1:511-514.

Li D, Zhou T, Zou L et al (2018) Extreme high-temperature events over East Asia in $1.5^{\circ} \mathrm{C}$ and $2^{\circ} \mathrm{C}$ warmer futures: Analysis of NCAR CESM low-warming experiments. Geophy Res Lett 45(3):15411550 .

Moss RH. Edmonds JA, Hibbard KA, Manning MR et al (2010) The next generation of scenarios for climate change research and assessment. Nature 463:747-756.

Niu X, Wang S, Tang J, Lee DK, Gutowsky W et al (2018) Ensemble evaluation and projection of climate extremes in China using RMIP models. Intern J Climatol 38(4):2039-2055.

Piani C, Haerter JO, Coppola E (2010) Statistical bias correction for daily precipitation in regional climate models over Europe. Theor Appl Climatol 99: 187-192.

Park IH, Min SK (2017) Role of convective precipitation in the relationship between subdaily extreme precipitation and temperature. J Climate 30(23):9527-9537.

Park C, Min SK (2019) Multi-RCM near-term projections of summer climate extremes over East Asia. Clim Dynam 52:4937-4952.

Park C, Min SK, Lee D, Cha DH, Suh MS et al (2016) Evaluation of multiple regional climate models for summer climate extremes over East Asia. Clim Dynam 46:2469-2486.

Park J-S, Kang H-S, Lee Y, Kim M-K (2011) Changes in the extreme daily rainfall in South Korea. Intern J Climatol 31:2290-2299.

Ruckstuhl C, Philipona R, Morland J, Ohmura A (2007) Observed relationship between surface specific humidity, integrated water vapor, and longwave downward radiation at different altitudes. J Geophys Res Atmos 112:1-7.

Sangelantoni L, Russo A, Gennaretti F (2019) Impact of bias correction and downscaling through quantile mapping on simulated climate change signal: a case study over Central Italy. Theor Appl Climatol 135:725-740. 
Seneviratne SI, Nicholls N, Easterling D, Goodess CM, Kanae S et al (2012) Changes in climate extremes and their impacts on the natural physical environment. In Managing the Risks of Extreme Events and Disasters to Advance Climate Change Adaptation. Special Report on Extremes by the Intergovernmental Panel on Climate Change.

Seo YA, Lee Y, Park J-S, Kim N-K, Cho C, Baek H-J (2015) Assessing changes in observed and future projected precipitation extremes in South Korea. Intern J Climatol 35:1069-1078.

Shin J, Lee T, Park T et al (2019a) Bias correction of RCM outputs using mixture distributions under multiple extreme weather influences. Theor Appl Climatol 137:201-216.

Shin Y, Lee Y, Choi JT, Park JS (2019b) Integration of max-stable processes and Bayesian model averaging to predict extreme climatic events in multi-model ensembles. Stoch Environ Res Risk Assess 33:47-57. doi:10.1007/s00477-018-1629-7

Sillmann J, Kharin VV, Zwiers FW et al (2013) Climate extremes indices in the CMIP5 multi-model ensemble: Part 2. Future projections. J Geophys Res doi:10.1002/jgrd.50188

Suh MS, Oh SG, Lee DK, Cha DH et al (2012) Development of new ensemble methods based on the performance skills of regional climate models over South Korea. J Clim 25:7067-7082.

Taylor KE (2001) Summarizing multiple aspects of model performance in a single diagram. J Geophys Res 106:7183-7192.

Tebaldi C, Hayhoe K, Arblaster JM, Meehl GA (2006) Going to the extremes: An intercomparison of model-simulated historical and future changes in extreme events. Clim Change 79:185-211.

Thibeault JM, Seth A (2014) Changing climate extremes in the Northeast United States: observations and projections from CMIP5. Clim Change 127:273-287.

Westra S, Alexander LV, Zwiers FW (2013) Global increasing trends in annual maximum daily precipitation. J Climate 26:3904-3918.

Wu FT, Wang SY, Fu CB, Qian Y et al (2016) Evaluation and projection of summer extreme precipitation over East Asia in the Regional Model Inter-comparison Project. Climate Res 69:45-58.

Yatagai A, Kamiguchi K, Arakawa O, Hamada A, Yasutomi N, Kitoh A (2012) APHRODITE: Constructing a long-term daily griddied precipitation dataset for Asia based on a dense network of rain gauges. Bull Amer Meteorol Soc 93:1401-1415.

Zhang X, Alexander L, Hegerl GC, Jones P et al (2011) Indices for monitoring changes in extremes based on daily temperature and precipitation data. WIREs Clim Change 2:851-870.

Zhou B, Wen QH, Xu Y, Song L et al (2014) Projected changes in temperature and precipitation extremes in China by the CMIP5 multimodel ensembles. J Climate 27:6591-6611

Zhu J, Forsee W, Schumer R, Gautam M (2013) Future projections and uncertainty assessment of extreme rainfall intensity in the United States from an ensemble of climate models. Clim Change 118(2):469-485. doi:10.1007/s10584-012-0639-6 


\section{Supplementary Material}

\section{S.1 Datasets}

We used the same dataset as in Kharin et al (2013) (hereafter referred to as K13), by following their approach. CMIP5 models analyzed in this study are listed in Table S3 together with the spatial resolutions of their atmospheric components. The number of ensemble simulations for each model and experiment is listed in Table S4. Output from 32 CMIP5 models was available for the historical experiment, from 22 codes for the RCP2.6 experiment, 31 models for the RCP4.5 experiment (not all years for some models), and 31 codes for the RCP8.5 experiment. The list of these tables are same to the tables in Supplementary Material of K13.

Observationally-based (or reanalysis) datasets used for the evaluation of temperature and rainfall extremes in the historical record are listed in Table S5. The used four reanalysis are the National Centers for Environmental Prediction-National Center for Atmospheric Research (NCEP-NCAR) reanalysis (Kalnay et al 1996) denoted hereafter as NCEP1, the European Centre for Medium-Range Weather Forecasts (ECMWF) ERA40 reanalysis (Uppala et al 2005), the NCEP-Department of Energy AMIP-II reanalysis (Kanamitsu et al 2002) denoted as NCEP2, and ECMWF ERA-Interim reanalysis (Dee et al 2011) denoted as ERA-I. Model-simulated extremes of non-overlapping 5-day rainfall rates (pentads) are also verified against the Climate Prediction Center Merged Analysis of Precipitation (CMAP) pentad dataset from the NCEPNCAR reanalysis (Xie and Arkin 1997), and the experimental global precipitation (GPCP) pentad dataset (Xie et al 2003).

\section{S.2 Methodology}

For the methods of data analysis, we follow the approach of Kharin et al (2013) and the references therein for analysis of climate extremes of near surface air temperature and daily rainfall amounts. For this purpose, we use a generalized extreme value (GEV) distribution that is fitted at every grid point to samples of annual temperature and rainfall extremes.

The GEVD is widely used to analyse univariate extreme values. The three types of extreme value distributions are sub-classes of GEVD. The cumulative distribution function of the GEVD is as follows:

$$
G(x)=\exp \left\{-\left(1+\xi \frac{x-\mu}{\sigma}\right)^{-1 / \xi}\right\},
$$

when $1+\xi(x-\mu) / \sigma>0$, where $\mu, \sigma$, and $\xi$ are the location, scale, and shape parameters, respectively. The particular case for $\xi=0$ in Eq. (1) is the Gumbel distribution, whereas the 
Table 3: The list of CMIP5 climate models analyzed in the present study and their horizontal and vertical resolutions. Model resolution is characterized by the size of a horizontal grid on which output is available from the model's atmospheric component and by the number of vertical levels. Spectral models are also characterized by their spectral truncations in brackets.

\begin{tabular}{|c|c|c|}
\hline Model & Institution & $\begin{array}{l}\text { Resolution } \\
(\text { Lon x Lat x Level \#) }\end{array}$ \\
\hline ACCESS1-0 & $\begin{array}{l}\text { Commonwealth Scientific \& Industrial Research Organiza- } \\
\text { tion/Bureau of Meteo., Australia }\end{array}$ & $192 \times 145 \mathrm{~L} 38$ \\
\hline bcc-csm1-1 & Beijing Climate Center, China Meteo. Admin. & $128 \times 64 \mathrm{~L} 26(\mathrm{~T} 42)$ \\
\hline bcc-csm1-1-m & Beijing Climate Center, China Meteo. Admin. & $320 \times 160$ \\
\hline BNU-ESM & Beijing Normal University, China & $128 \times 64 \mathrm{~L} 26(\mathrm{~T} 42)$ \\
\hline CanESM2 & Canadian Centre for Climate Modelling \& Analysis & $128 \times 64 \mathrm{~L} 35(\mathrm{~T} 63)$ \\
\hline CCSM4 & National Center for Atmospheric Research, USA & $288 \times 192 \mathrm{~L} 26$ \\
\hline CMCC-CM & Centro Euro-Mediterraneo per I Cambiamenti, Italy & $480 \times 240 \mathrm{~L} 31(\mathrm{~T} 159)$ \\
\hline CMCC-CMS & Centro Euro-Mediterraneo per I Cambiamenti, Italy & $192 \times 96$ \\
\hline CNRM-CM5 & $\begin{array}{l}\text { Centre National de Recherches Meteorologiques, Meteo- } \\
\text { France }\end{array}$ & $256 \times 128 \mathrm{~L} 31(\mathrm{~T} 127)$ \\
\hline CSIRO-Mk3-6-0 & $\begin{array}{l}\text { Australian Commonwealth Scientific \& Industrial Research } \\
\text { Organization }\end{array}$ & $192 \times 96 \mathrm{~L} 18(\mathrm{~T} 63)$ \\
\hline FGOALS-g2 & $\begin{array}{l}\text { Inst. Atmospheric Physics, Chinese Academy of Sciences, } \\
\text { Tsinghua University }\end{array}$ & $128 \times 60 \mathrm{~L} 26$ \\
\hline FGOALS-s2 & Inst. Atmospheric Physics, Chinese Academy of Sciences & $128 \times 108 \mathrm{~L} 26$ \\
\hline GFDL-CM3 & Geophysical Fluid Dynamics Laboratory, USA & $144 \times 90 \mathrm{~L} 48$ \\
\hline GFDL-ESM2G & Geophysical Fluid Dynamics Laboratory, USA & $144 \times 90 \mathrm{~L} 24$ \\
\hline GFDL-ESM2M & Geophysical Fluid Dynamics Laboratory, USA & $144 \times 90 \mathrm{~L} 24$ \\
\hline HadGEM2-AO & UK Met Office Hadley Centre & $96 \times 73 \mathrm{~L} 19$ \\
\hline HadGEM2-CC & UK Met Office Hadley Centre & $192 \times 145 \mathrm{~L} 40$ \\
\hline HadGEM2-ES & UK Met Office Hadley Centre & $192 \times 145 \mathrm{~L} 40$ \\
\hline inmcm4 & Institute for Numerical Mathematics, Russia & $180 \times 120 \mathrm{~L} 21$ \\
\hline IPSL-CM5A-LR & Inst. Pierre-Simon Laplace, France & $96 \times 96 \mathrm{~L} 39$ \\
\hline IPSL-CM5A-MR & Inst. Pierre-Simon Laplace, France & $144 \times 143 \mathrm{~L} 39$ \\
\hline IPSL-CM5B-LR & Inst. Pierre-Simon Laplace, France & $96 \times 96 \mathrm{~L} 39$ \\
\hline MIROC5 & Model for Interdisciplinary Research on Climate, Japan & $256 \times 128 \mathrm{~L} 40(\mathrm{~T} 85)$ \\
\hline MIROC-ESM & Model for Interdisciplinary Research on Climate, Japan & $128 \times 64 \mathrm{~L} 80(\mathrm{~T} 42)$ \\
\hline MIROC-ESM-CHEM & Model for Interdisciplinary Research on Climate, Japan & $128 \times 64 \mathrm{~L} 80(\mathrm{~T} 42)$ \\
\hline MPI-ESM-LR & Max Planck Institute for Meteorology, Germany & $192 \times 96 \mathrm{~L} 47(\mathrm{~T} 63)$ \\
\hline MPI-ESM-MR & Max Planck Institute for Meteorology, Germany & $192 \times 96 \mathrm{~L} 95(\mathrm{~T} 63)$ \\
\hline MRI-CGCM3 & Meteorological Research Institute, Japan & $320 \times 160 \mathrm{~L} 48(\mathrm{~T} 159)$ \\
\hline NorESM1-M & Norwegian Climate Centre & $144 \times 96 \mathrm{~L} 26$ \\
\hline
\end{tabular}


Table 4: The rainfall simulation codes used in this study are listed. The symbol and number in blanket are for temperature numerical models. Model output is generally available for year 1850-2005 for the historical experiment, and for years 2006-2100 for the RCP experiments.

\begin{tabular}{lllll}
\hline \hline Model & Historical & $\mathrm{RCP} 2.6$ & $\mathrm{RCP} 4.5$ & $\mathrm{RCP} 8.5$ \\
\hline ACCESS1-0 & $\mathrm{O}$ & $\mathrm{X}$ & $\mathrm{O}$ & $\mathrm{X}$ \\
BCC-CSM1-1 & $\mathrm{O}(\mathrm{X})$ & $\mathrm{O}(\mathrm{X})$ & $\mathrm{O}$ & $\mathrm{O}$ \\
BCC-CSM1-1-m & $\mathrm{O}$ & $\mathrm{O}$ & $\mathrm{O}$ & $\mathrm{O}$ \\
BNU-ESM & $\mathrm{O}(\mathrm{X})$ & $\mathrm{O}$ & $\mathrm{O}$ & $\mathrm{O}$ \\
CanESM2 & $\mathrm{O}$ & $\mathrm{O}$ & $\mathrm{O}$ & $\mathrm{O}$ \\
CCSM4 & $\mathrm{O}$ & $\mathrm{O}$ & $\mathrm{O}$ & $\mathrm{O}$ \\
CMCC-CM & $\mathrm{O}$ & $\mathrm{X}$ & $\mathrm{O}$ & $\mathrm{X}$ \\
CMCC-CMS & $\mathrm{O}$ & $\mathrm{X}$ & $\mathrm{O}$ & $\mathrm{X}$ \\
CNRM-CM5 & $\mathrm{O}$ & $\mathrm{O}$ & $\mathrm{O}$ & $\mathrm{O}$ \\
CSIRO-Mk3-6-0 & $\mathrm{O}$ & $\mathrm{O}$ & $\mathrm{O}$ & $\mathrm{O}$ \\
FGOALS-g2 & $\mathrm{O}(\mathrm{X})$ & $\mathrm{O}(\mathrm{X})$ & $\mathrm{O}(\mathrm{X})$ & $\mathrm{O}(\mathrm{X})$ \\
FGOALS-s2 & $\mathrm{O}$ & $\mathrm{X}$ & $\mathrm{X}$ & $\mathrm{O}(\mathrm{X})$ \\
GFDL-CM3 & $\mathrm{O}$ & $\mathrm{O}$ & $\mathrm{O}$ & $\mathrm{O}$ \\
GFDL-ESM2G & $\mathrm{O}$ & $\mathrm{O}$ & $\mathrm{O}$ & $\mathrm{O}$ \\
GFDL-ESM2M & $\mathrm{O}$ & $\mathrm{O}$ & $\mathrm{O}$ & $\mathrm{O}$ \\
HadCM3-AO & $\mathrm{O}(\mathrm{X})$ & $\mathrm{X}$ & $\mathrm{O}(\mathrm{X})$ & $\mathrm{O}(\mathrm{X})$ \\
HadGEM2-CC & $\mathrm{O}$ & $\mathrm{X}$ & $\mathrm{O}$ & $\mathrm{O}$ \\
HadGEM2-ES & $\mathrm{O}$ & $\mathrm{O}$ & $\mathrm{O}$ & $\mathrm{O}$ \\
INMCM4 & $\mathrm{O}$ & $\mathrm{X}$ & $\mathrm{O}$ & $\mathrm{O}$ \\
IPSL-CM5A-LR & $\mathrm{O}$ & $\mathrm{O}$ & $\mathrm{O}$ & $\mathrm{O}$ \\
IPSL-CM5A-MR & $\mathrm{O}$ & $\mathrm{O}$ & $\mathrm{O}$ & $\mathrm{O}$ \\
IPSL-CM5B-LR & $\mathrm{O}$ & $\mathrm{X}$ & $\mathrm{O}$ & $\mathrm{X}(\mathrm{O})$ \\
MIROC5 & $\mathrm{O}$ & $\mathrm{O}$ & $\mathrm{O}$ & $\mathrm{O}$ \\
MIROC-ESM & $\mathrm{O}$ & $\mathrm{O}$ & $\mathrm{O}$ & $\mathrm{O}$ \\
MIROC-ESM-CHEM & $\mathrm{O}$ & $\mathrm{O}$ & $\mathrm{O}$ & $\mathrm{O}$ \\
MPI-ESM-LR & $\mathrm{O}$ & $\mathrm{O}$ & $\mathrm{O}$ & $\mathrm{O}$ \\
MPI-ESM-MR & $\mathrm{O}$ & $\mathrm{O}$ & $\mathrm{O}$ & $\mathrm{O}$ \\
MRI-CGCM3 & $\mathrm{O}$ & $\mathrm{O}$ & $\mathrm{O}$ & $\mathrm{O}$ \\
NorESM1-M & $\mathrm{O}$ & $\mathrm{O}$ & $\mathrm{O}$ & $\mathrm{O}$ \\
\hline Total \#of models & $29(25)$ & $21(19)$ & $28(26)$ & $25(23)$ \\
\hline
\end{tabular}


Table 5: Reanalysis and observation-base datasets used in this study for validation of temperature and precipitation extremes.

\begin{tabular}{lll}
\hline \hline Label & Grid size & Dataset and reference \\
\hline ERA40 & $144 \times 73$ & ECMWF ERA-40 reanalysis (Uppala et al., 2005) \\
ERA-I & $240 \times 121$ & ECMWF ERA-Interim reanalysis (Dee et al., 2011) \\
NCEP1 & $192 \times 94$ & NCEP-NCAR reanalysis (Kalnay et al., 1996) \\
NCEP2 & $192 \times 94$ & $\begin{array}{l}\text { NCEP-DOE (Department Of Energy) AMIP-II reanalysis } \\
\text { (Kanamitsu et al., 2002) }\end{array}$ \\
CMAP & $144 \times 72$ & $\begin{array}{l}\text { Climate Prediction Center Merged Analysis of Precipitation } \\
\text { (Xie and Arkin, 1997) }\end{array}$ \\
GPCP & $144 \times 72$ & Global Precipitation Climatology Project (Xie et al., 2003) \\
\hline \hline
\end{tabular}

cases for $\xi>0$ and $\xi<0$ are known as the Fréchet and the negative Weibull distributions, respectively (Coles, 2001).

Assuming the data, the annual maxima of daily rainfall in this study, follow (approximately) a GEV distribution, the parameters can be estimated by using the maximum likelihood method (e.g., Coles 2001) or the method of L-moments estimation. The maximum likelihood estimator is less efficient than the L-moments estimator in small samples for typical shape parameter values (Hosking 1990). The L-moments method is used in this study because relatively short 30-year samples are analyzed for each comparison period. Moreover, the formulae used to obtain the L-moments estimator are simple compared with obtaining the maximum likelihood estimator which needs an iterative computation until convergence. The L-moments estimator are

$$
\hat{\xi}=7.8590 c+2.9554 c^{2}
$$

where

$$
c=\frac{2 l_{2}}{l_{3}+3 l_{2}}-\frac{\ln (2)}{\ln (3)}
$$

and $l_{2}$ and $l_{3}$ are the sample second and third L-moments (Hosking, 1990). The other parameters are then given by

$$
\begin{aligned}
\sigma & =\frac{\hat{\xi} l_{2}}{\Gamma(1+\hat{\xi})\left(1-2^{-\hat{\xi}}\right)} \\
\mu & =l_{1}+\frac{\hat{\sigma}[\Gamma(1+\hat{\xi})-1]}{\hat{\xi}},
\end{aligned}
$$

where $l_{1}$ is the first sample L-moment. The actual estimates are obtained with the feasibility modification of Dupuis and Tsao (1998). 
When observations depend on time as a covariate, we employ the maximum likelihood method for estimating the parameters of a GEV distribution as in Coles (2001) or Kharin and Zwiers (2005). The parameters are estimated for each year from overlapping 51-year time windows. The location and scale parameters are assumed to depend linearly on time while the shape parameter is assumed to be time-invariant. An advantage of the maximum likelihood method is that time covariates can be included, which potentially allows extreme value statistics to be estimated more accurately for each individual year. In contrast, L-moment estimates are representative of a whole 20-year time slice (K13).

It can be helpful to describe changes in extremes in terms of changes in extreme quantiles. These are obtained by inverting (1):

$$
z_{p}=\mu-\frac{\sigma}{\xi}\left[1-\{-\log (1-p)\}^{-\xi}\right]
$$

where $G\left(z_{p}\right)=1-p$. Here, $z_{p}$ is known as the return level associated with the waiting time (or return period) $1 / p$, since the value $z_{p}$ is expected to be exceeded on average once every $1 / p$ years (Coles 2001). For example, a 20-year (50-year) return level is computed as the 95th (98th) percentile of the fitted GEVD. These return levels and waiting times are used as the main quantities in this study.

The projected changes in temperature and rainfall extremes are determined relative to the 1986-2005 reference period and are also expressed in terms of the corresponding changes in waiting times for climate extremes simulated in the reference period. The projected multimodel median changes are assessed with the Wilcoxon signed-rank test.

Following K13, we also estimate the dependence of local changes in extreme rainfall on mean temperature changes at the same location as simulated in the CMIP5 ensemble. This is done by fitting a GEV distribution to annual rainfall extremes at each grid point in the historical and all available RCP experiments for each model with the three GEV parameters linearly depending on mean temperature change at the same grid point. The resulting six parameters are estimated by the method of maximum likelihood. Once the parameters are estimated, the return levels and their changes per unit of warming are obtained by computing the corresponding quantiles of the GEV distribution (K13). For more technical details, readers are recommended to see the Supplementary Material of K13.

\section{S.3 Simulated late 20th century climate extremes over East Asia}

\section{S.3.1 Evaluation of simulation models}

Figure S9 shows the Taylor diagrams (Taylor 2001) of 29 CMIP5 models for the 20-year return levels of the largest daily rainfall (top left panel, $\mathrm{R}_{20}$ ), coldest temperature (top right panel, 

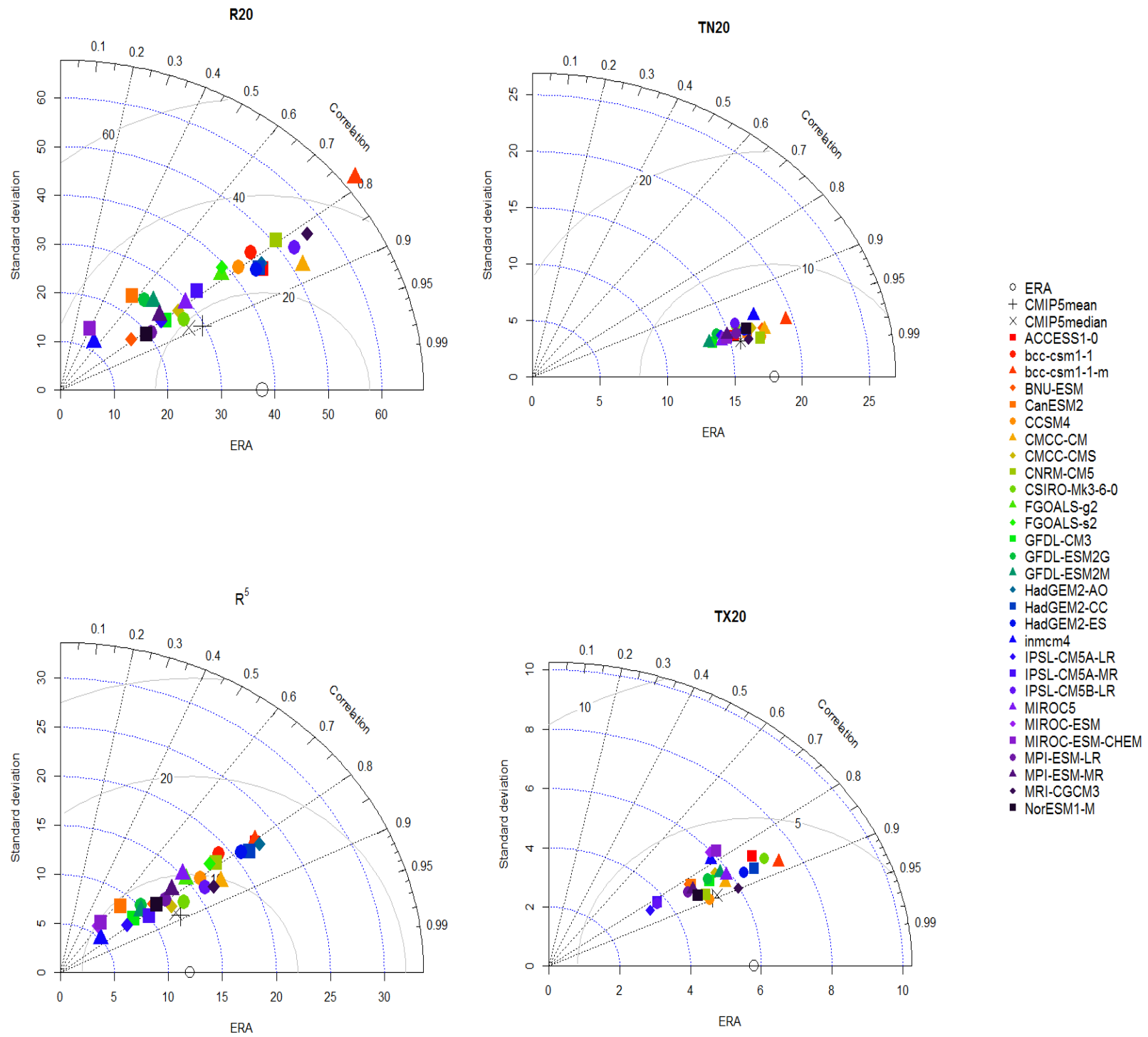

Figure 9: Taylor diagrams for $\mathrm{R}_{20}$ (top left panel), $\mathrm{TN}_{20}$ (top right panel), $\mathrm{R}_{20}^{5}$ (bottom left panel), and $\mathrm{TX}_{20}$ (bottom right panel) are listed, where $\mathrm{R}_{20}, \mathrm{TN}_{20}, \mathrm{R}_{20}^{5}$, and $\mathrm{TX}_{20}$ are 20-year return levels of 1986-2005 annual largest daily and 5-day rainfalls (mm), annual coldest and warmest temperatures $\left({ }^{\circ} \mathrm{C}\right)$, respectively. 
$\mathrm{TN}_{20}$ ), maximum 5-day precipitation (bottom left, $\mathrm{R}^{5}$ ), and warmest temperature (bottom right panel, $\mathrm{TX}_{20}$ ). The azimuthal angle represents the Pearson correlation coefficient (gray contours); the radial distance from the origin represents the normalized standard deviation of the scenario models and observations (blue dashed contours); and the distance from the point of observation on the x-axis represents the normalized root mean squared error (black dashed radial grid).

For the largest daily rainfall, the standard deviation (SD) of the observation (ERA-I) is $37.7 \mathrm{~mm}$, whereas those of the CMIP5 are distributed between $11.7 \mathrm{~mm}$ and $70.2 \mathrm{~mm}$. The pattern correlations between the observation and multimodels are between 0.39 and 0.86 , and the root mean squared errors (RMSEs) of the CMIP5 models are between $23.1 \mathrm{~mm}$ and $36.2 \mathrm{~mm}$. For the maximum 5-day precipitation, the SD of ERA-I is $12.0 \mathrm{~mm}$, whereas those of the CMIP5 are between $5.0 \mathrm{~mm}$ and $23 \mathrm{~mm}$. The pattern correlations are from 0.6 to 0.85 , and the RMSEs of the models are between $7.5 \mathrm{~mm}$ and $17 \mathrm{~mm}$. The CMIP5 models for the maximum 5-day precipitation have higher correlations to observations with less variations compared with those for the largest daily rainfall.

For the coldest temperature, the SD of the observation is $18.0^{\circ} \mathrm{C}$, and those of the CMIP5 are between $13.4^{\circ} \mathrm{C}$ and $19.5^{\circ} \mathrm{C}$. The correlations between ERA-I and the multimodels are between 0.94 and 0.97 , and the RMSEs of the CMIP5 models are between $4.5^{\circ} \mathrm{C}$ and $8.5^{\circ} \mathrm{C}$. Lastly, for the warmest temperature, the $\mathrm{SD}$ of the observation is $5.8^{\circ} \mathrm{C}$, and those of the CMIP5 are between $3.4^{\circ} \mathrm{C}$ and $7.4^{\circ} \mathrm{C}$. The correlations are between 0.76 and 0.89 , and the RMSEs of the models are between $2.9^{\circ} \mathrm{C}$ and 5.1. The CMIP5 models for the coldest temperature have higher correlations to the observations with more variations compared to those for the warmest temperature .

Table 6: Three quartiles obtained from CMIP5 multimodel ensemble and the median from the reanalysis datasets for spatially averaged 20-year return levels of 1986-2005 annual warmest temperature $\left(\mathrm{TX}_{20}\right)$ and annual coldest temperature $\left(\mathrm{TN}_{20}\right)$.

\begin{tabular}{c|ccc|ccc}
\hline & \multicolumn{3}{|c|}{$\mathrm{TX}_{20}\left({ }^{\circ} \mathrm{C}\right)$} & \multicolumn{3}{c}{$\mathrm{TN}_{20}\left({ }^{\circ} \mathrm{C}\right)$} \\
Source & Globe & East Asia & Korea & Globe & East Asia & Korea \\
\hline CMIP5 75\% & 26.60 & 32.41 & 32.00 & 0.20 & -8.97 & -5.87 \\
CMIP5 50\% & 26.20 & 31.21 & 31.14 & -0.80 & -10.52 & -7.55 \\
CMIP5 25\% & 25.70 & 29.60 & 29.97 & -1.40 & -11.13 & -8.89 \\
ERA-I & 25.60 & 30.74 & 30.77 & 0.10 & -4.86 & -4.00 \\
NCEP2 & 26.40 & 31.49 & 32.73 & -2.80 & -7.92 & -7.67 \\
\hline
\end{tabular}



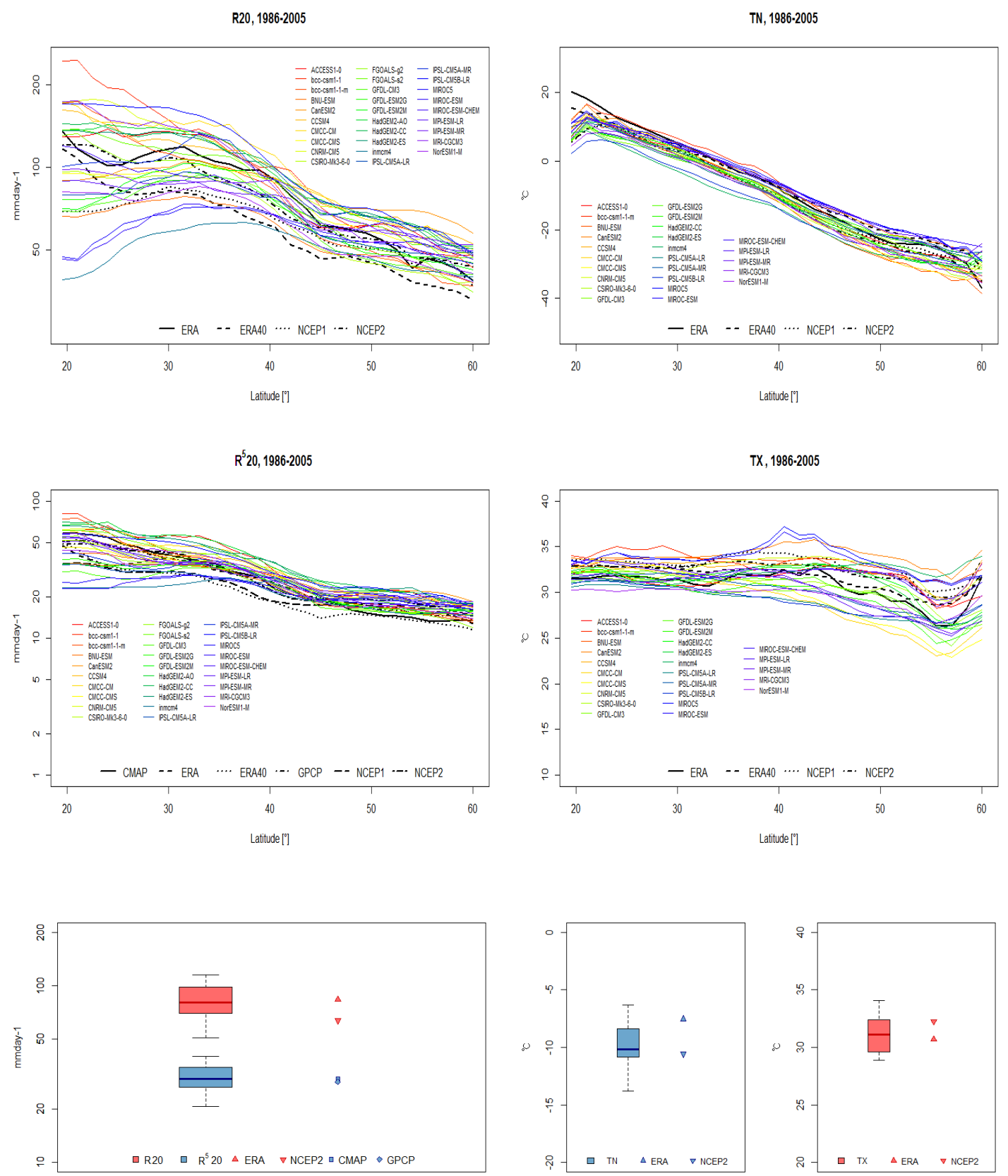

Figure 10: Zonally averaged 20-year return levels of 1986-2005 annual largest daily rainfall $\left(\mathrm{R}_{20}\right.$, top left panel), the annual coldest temperature ( $T N$, top right panel), non-overlapping 5 -day mean rainfall $\left(\overline{\mathrm{R}}_{20}^{5}\right.$, middle left panel), and the annual warmest temperature $(T X$, middle right panel) as simulated by CMIP5 models plotted on a log scale. Rainfall extremes estimated from the reanalysis are displayed in black. The CMAP and GPCP pentad rainfall extremes are displayed by brown curves. Bottom panel ${ }_{31}$ Box-and-whisker plots of simulated regionally averaged 1986-2005 $R_{20}$ and $\overline{\mathrm{R}}_{20}^{5}$. Symbols to the right of the box-and-whisker plots indicate the corresponding statistics estimated from the reanalyses and CMAP pentad dataset. 
Table 7: Three quartiles obtained from CMIP5 multimodel ensemble and the median from the reanalysis datasets for spatially averaged 20-year return levels of annual largest daily rainfall $\left(\mathrm{R}_{20}\right)$ and for annual largest pentad precipitation $\left(\overline{\mathrm{R}}_{20}^{5}\right)$.

\begin{tabular}{c|ccc|ccc}
\hline & \multicolumn{3}{|c|}{$\mathrm{R}_{20}(\mathrm{~mm} /$ day $)$} & \multicolumn{3}{c}{$\overline{\mathrm{R}}_{20}^{5}(\mathrm{~mm} /$ day $)$} \\
Source & Globe & East Asia & Korea & Globe & East Asia & Korea \\
\hline CMIP5 75\% & 76.00 & 98.07 & 127.37 & 29.00 & 33.83 & 40.68 \\
CMIP5 50\% & 65.00 & 80.02 & 108.60 & 26.00 & 29.50 & 36.25 \\
CMIP5 25\% & 52.00 & 69.72 & 94.06 & 23.00 & 26.21 & 32.80 \\
ERA-I & 67.00 & 83.49 & 118.02 & 22.00 & 26.43 & 35.98 \\
NCEP2 & 84.00 & 76.94 & 87.99 & 32.00 & 28.34 & 29.50 \\
CMAP & - & - & - & 24.00 & 29.26 & 44.11 \\
\hline
\end{tabular}

\section{S.3.2 Reanalysis data and simulation models}

The 20-year return levels of 1986-2005 annual warmest temperature and coldest temperature for the globe, East Asia, and Korea are summarized in Table S6. The quartiles of CMIP5 multimodel ensembles (MME) of 20-year return level in ERA-I and NCEP2 (Dee et al. 2011; Kanamitsu et al. 2002) are presented. Three quartiles of rainfall extremes for MME and median values from the reanalysis data are provided in Table S7. The return levels $R_{20}$ and $\overline{\mathrm{R}}_{20}^{5}$ obtained by CMIP5 MME for 1986-2005 over Korea, EA, and the globe are compared. These statistics are obtained by using the method of L-moments.

Figure S10 shows the zonally averaged 20-year return levels of 1986-2005 annual largest daily rainfall $\left(\mathrm{R}_{20}\right.$, top panel), the annual coldest temperature ( $T N$, top right panel), nonoverlapping 5-day mean rainfall $\left(\overline{\mathrm{R}}_{20}^{5}\right.$, middle left panel), and the annual warmest temperature ( $T X$, middle right panel) as simulated by CMIP5 models plotted on a log scale. The CMAP and GPCP pentad rainfall extremes (Xie and Arkin 1997; Xie et al 2003) were used for obtaining $\overline{\mathrm{R}}_{20}^{5}$. Note that the reanalysis datasets ERA40 and NCEP1 (Uppala et al 2005; Kalnay et al 1996) were also used in drawing this figure. In addition, box-and-whisker plots of regionally averaged statistics are provided, which are obtained from the reanalyses and CMAP and GPCP pentad datasets.

Figure S11 shows contour maps of 20-year return level of the annual largest daily rainfall for the reference period (1986-2005) obtained from four different reanalysis datasets (ERA-I, ERA40, NCEP1, and NCEP2) across EA. Figure S12 is contour maps of 20-year return level of the annual maximum 5-day rainfall for the reference period obtained from 6 different reanalyses (ERA-I, ERA40, NCEP1, NCEP2, CMAP and GPCP). Figure S13 is contour plot of 20-year 
return level of the annual largest pentad precipitation obtained from CMIP5 ensemble for the historical data.
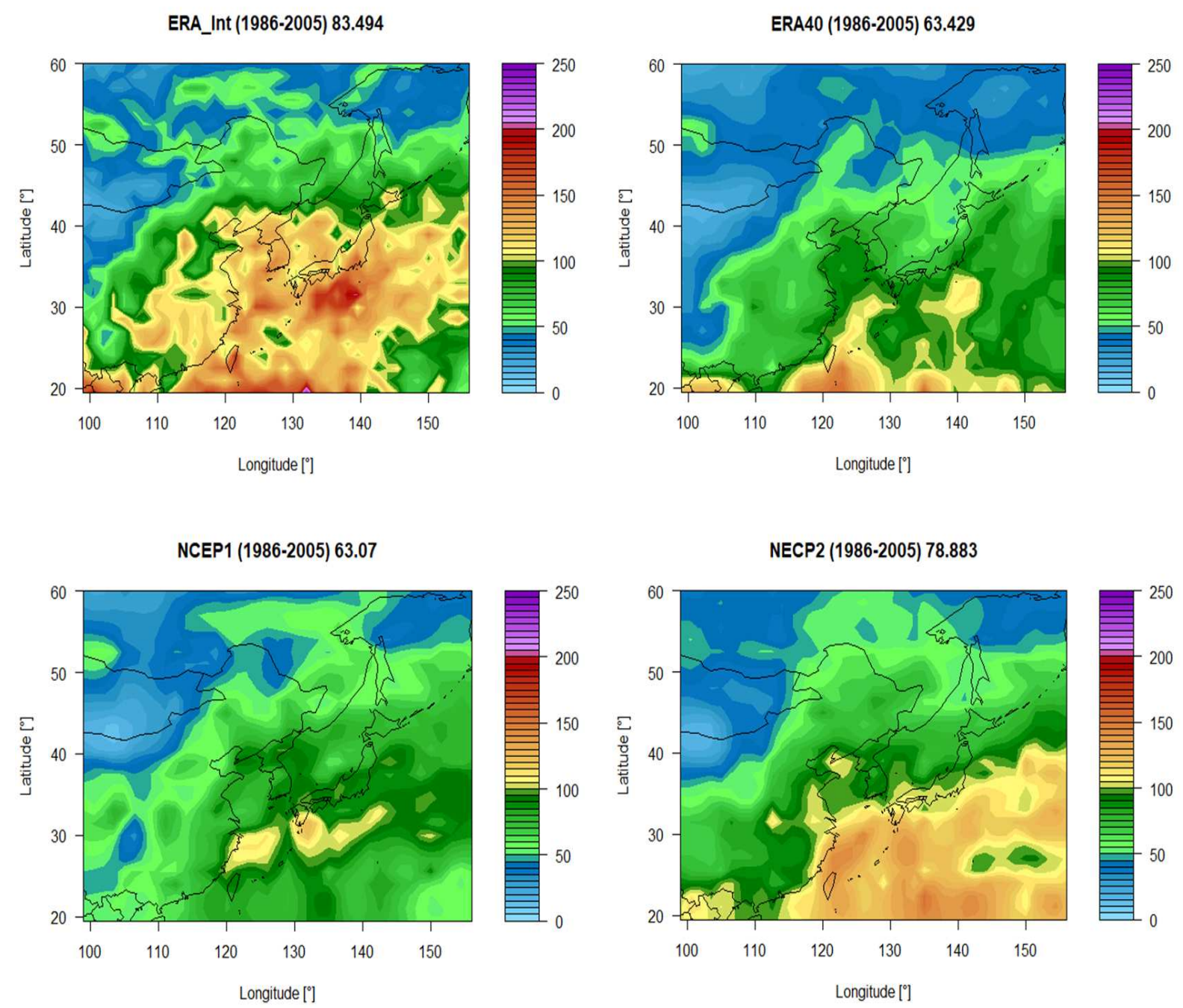

Figure 11: Contour maps of 20-year return level of the annual largest daily rainfall for the reference period (1986-2005) obtained from 4 different reanalysis datasets (ERA-I, ERA40, NCEP1, and NCEP2). 
ERA_Int (1986-2005) 26.426

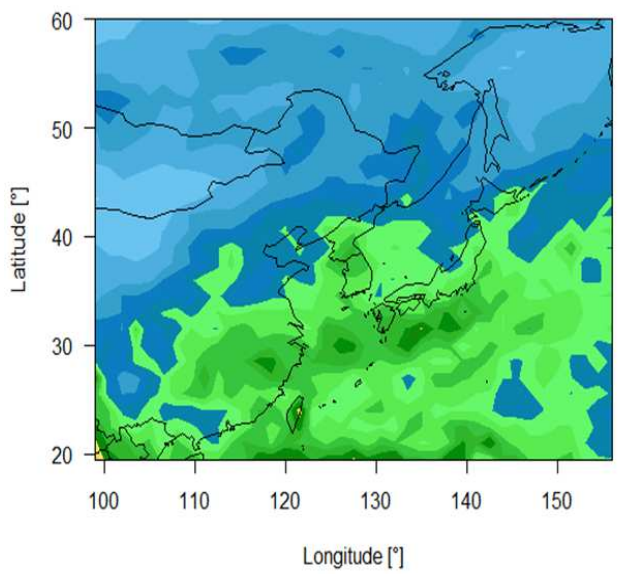

NCEP1 (1986-2005) 23.197

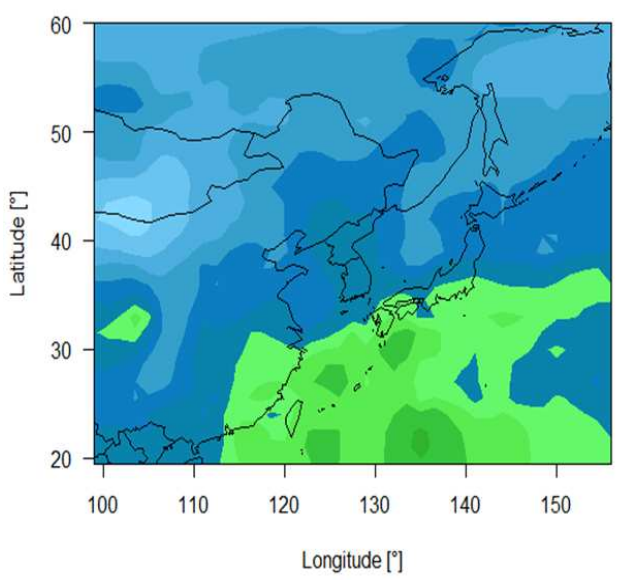

CMAP (1986-2005) 29.612

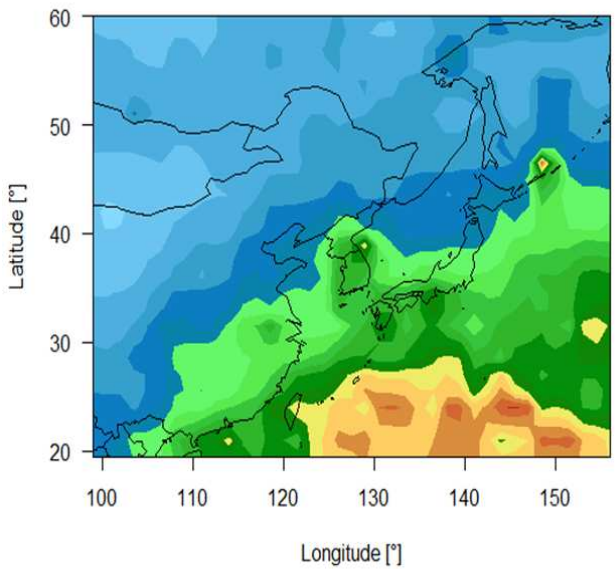

ERA40 (1986-2005) 22.547

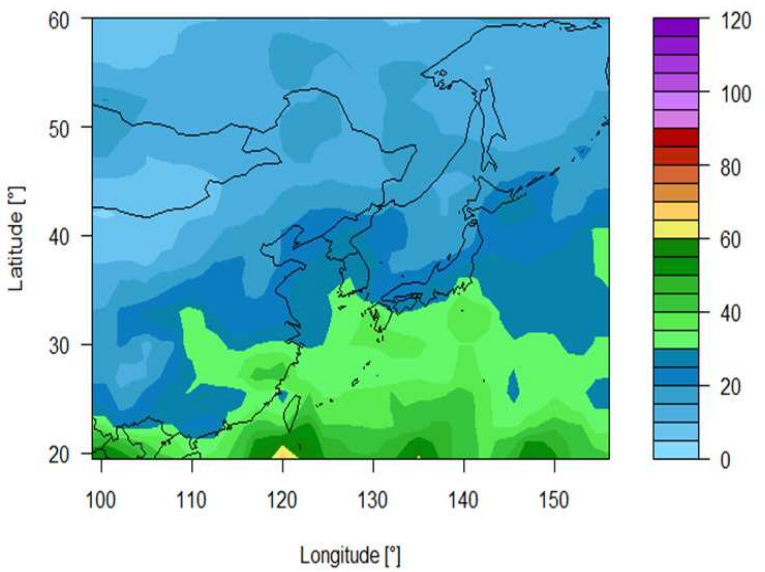

NECP2 (1986-2005) 29.422
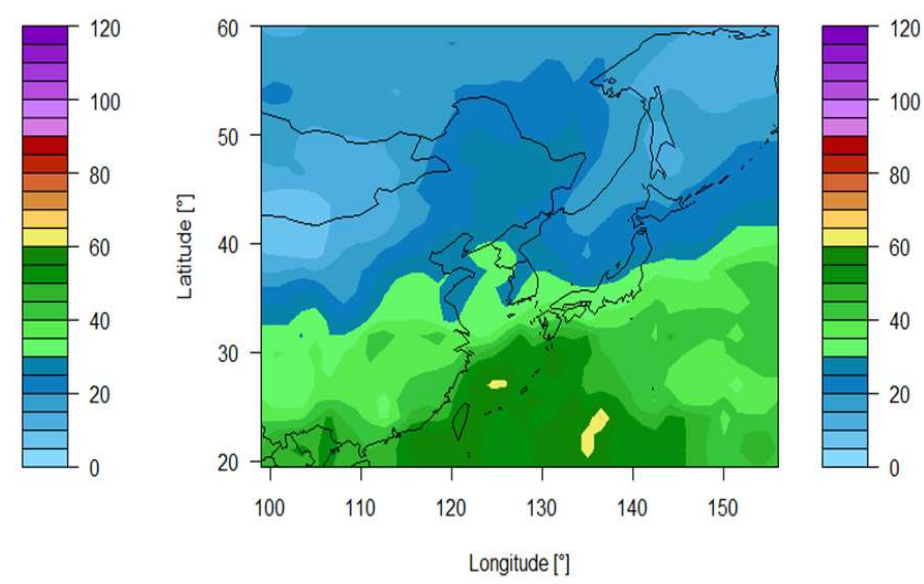

GPCP (1986-2005) 28.572
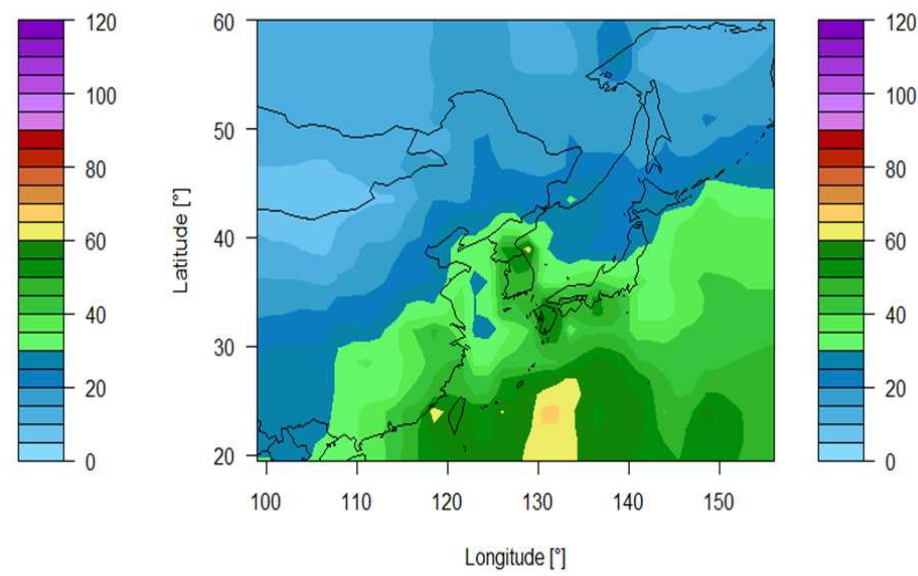

Figure 12: Contour maps of 20-year return level of the annual largest 5-day rainfall for the reference period (1986-2005) obtained from 6 different reanalysis datasets (ERA-I, ERA40, NCEP1, NCEP2, CMAP and GPCP). 


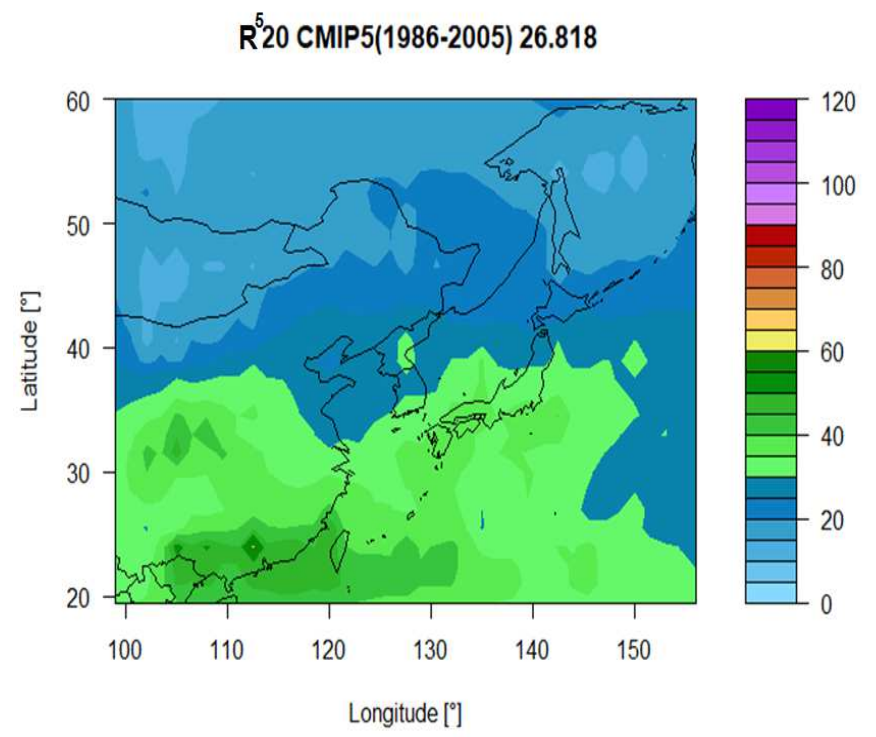

Figure 13: Contour map of 20-year return level of the annual largest 5-day rainfall for the reference period (1986-2005) obtained from CMIP5 ensemble for the historical pentad data.

\section{S.4 Projected future changes in climate extremes over East Asia}

\section{S.4.1 Changes in temperature extremes}

Figure S14 shows contour maps of the future relative changes of the 20-year return levels in cold temperature extremes $\left(\mathrm{TN}_{20}\right)$ and in warm temperature extremes $\left(\mathrm{TX}_{20}\right)$ for $2081-2100$ relative to 1986-2005 from the CMIP5 ensemble in the three RCP scenarios. Figure S15 displays the box-and-whisker plots of the future changes in temperature extremes as simulated by CMIP5 models in 2016-2035, 2046-2065, and 2081-2100 relative to 1986-2005.

In the Figures 3 and 4 in the paper, the changes of $T N_{20}$ over EA by the end of 21st century are $1.9^{\circ} \mathrm{C}, 3.2^{\circ} \mathrm{C}$, and $6.7^{\circ} \mathrm{C}$ for RCP2.6, RCP 4.5 , and $\mathrm{RCP} 8.5\left(0.9^{\circ} \mathrm{C}, 2.0^{\circ} \mathrm{C}\right.$, and $4.8^{\circ} \mathrm{C}$ for $\left.T X_{20}\right)$, respectively. These values over Korea are $1.3^{\circ} \mathrm{C}, 2.4^{\circ} \mathrm{C}$, and $7.0^{\circ} \mathrm{C}$ for $T N_{20}$, and $1.6^{\circ} \mathrm{C}, 2.6^{\circ} \mathrm{C}$, and $5.5^{\circ} \mathrm{C}$ for $T X_{20}$.

\section{S.4.2 Changes in rainfall extremes}

Figure S16 shows the changes of the annual mean precipitation for future three periods from CMIP5 MME relative to the period 1986-2005. Figure S17 shows the box-and-whisker plots of relative changes (\%) in the regionally averaged 20-year return levels of annual extremes of daily 

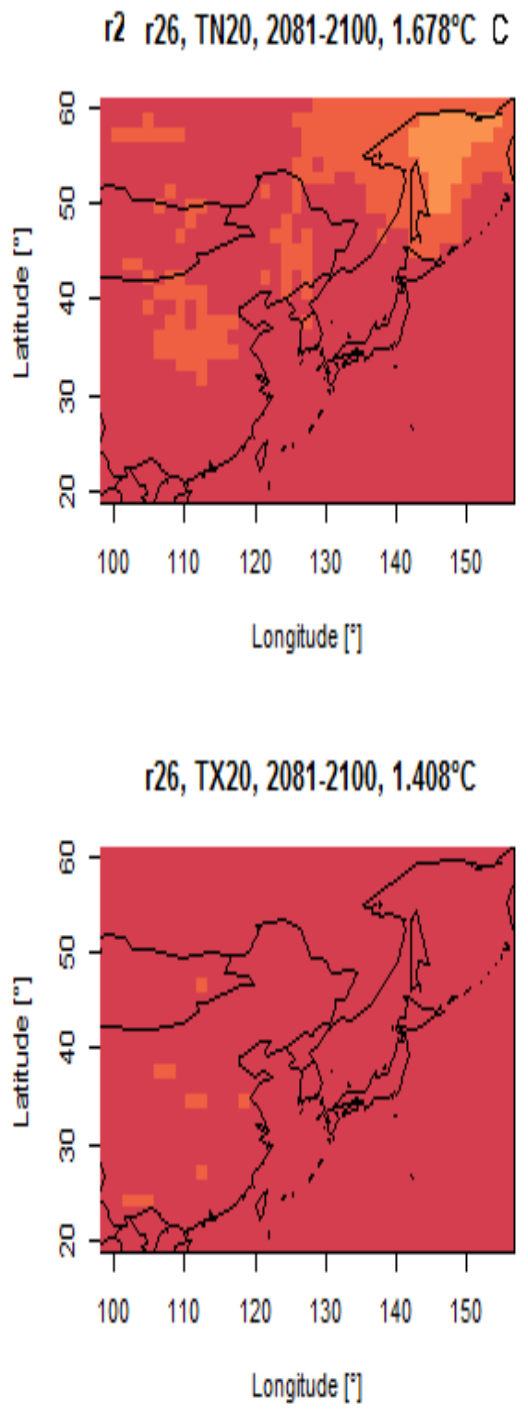

r85, TN20, 2081-2100, 6.121 ${ }^{\circ} \mathrm{C}$

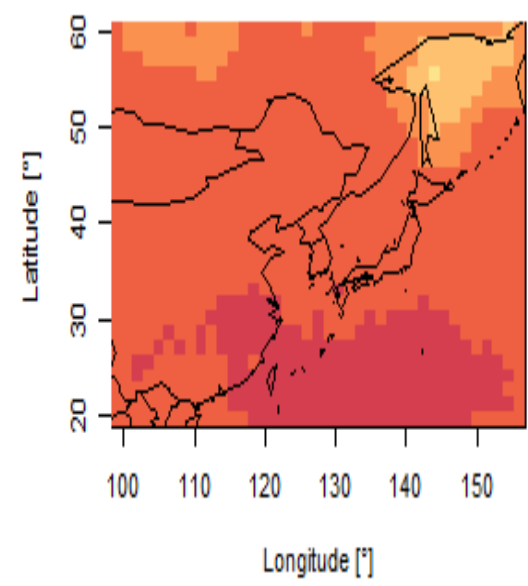

ז45, TX20, 2081-2100, 2..4 C

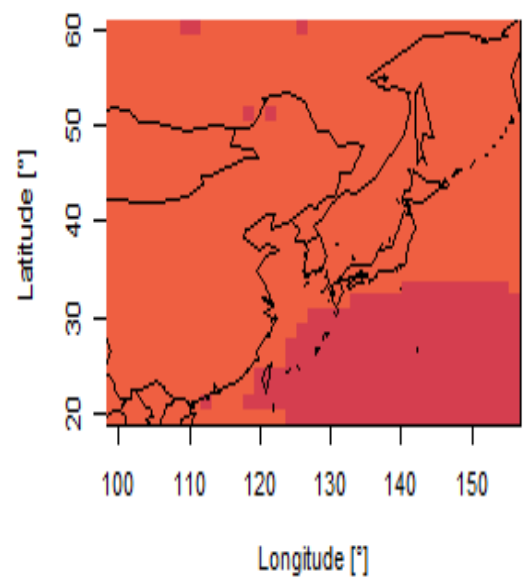

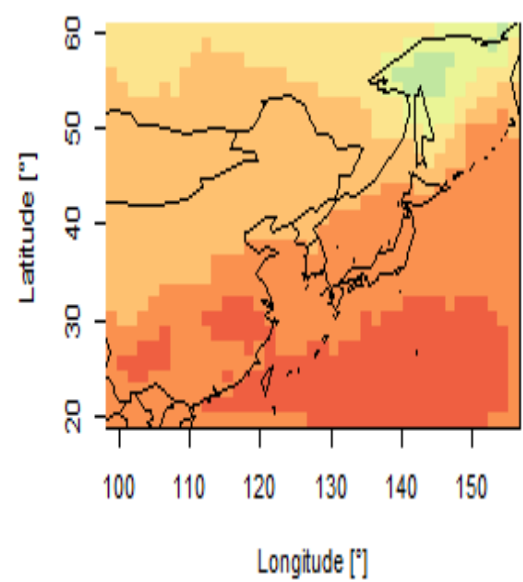

r85, TX20, $2081-2100,5.081^{\circ} \mathrm{C}$

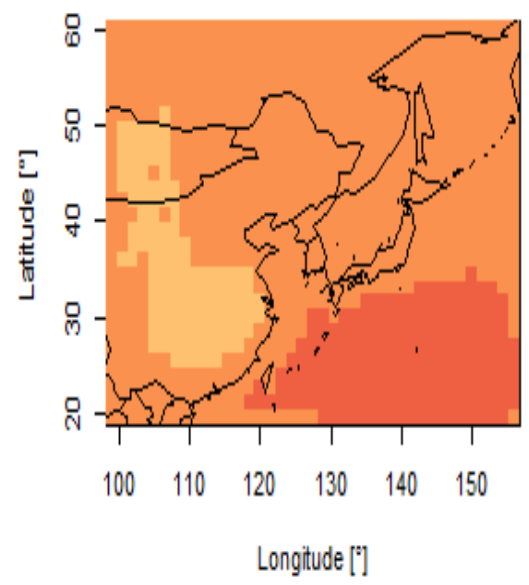

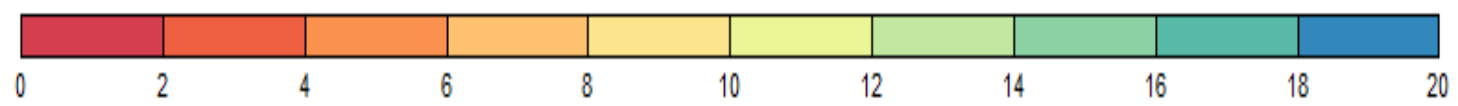

Figure 14: Top row: CMIP5 median future relative changes (\%) in 20-year return levels of annual coldest temperature $T N_{20}$ simulated in 2081-2100 relative to 1986-2005 in RCP2.6 (left), RCP4.5 (middle), and RCP8.5 (right). Bottom row: Same as the above but for annual warmest temperature $T X_{20}$. 
$\Delta \mathrm{TN},{ }^{\mathrm{C}}, \mathbf{2 0 1 6 - 2 0 3 5}$

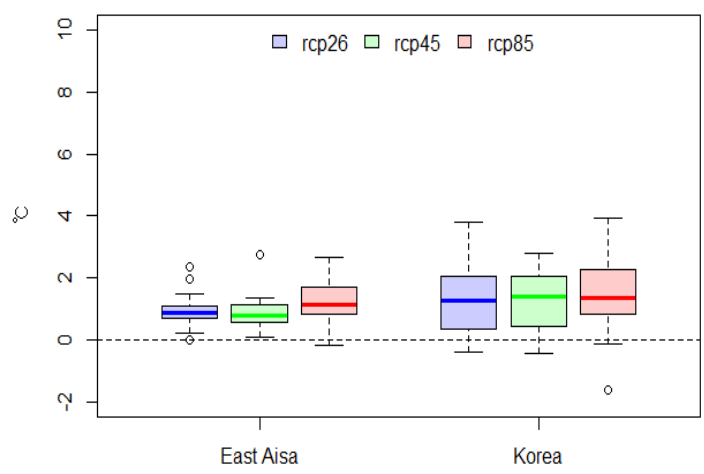

$\Delta$ TN, ${ }^{\mathrm{C}}, \mathbf{2 0 4 6 - 2 0 6 5}$

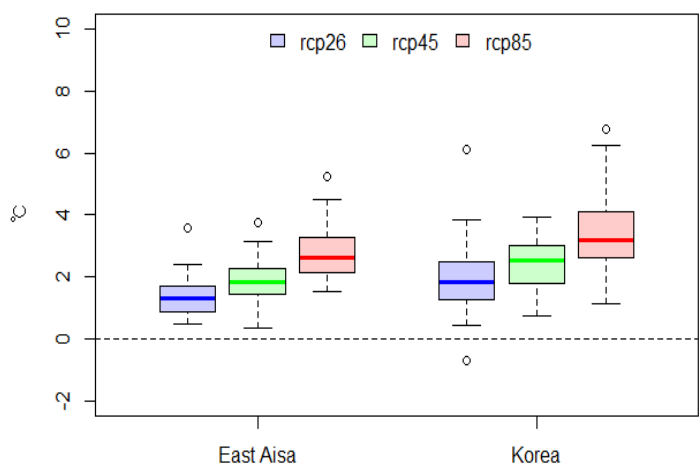

$\Delta \mathrm{TN}, \mathrm{C}, \mathbf{2 0 8 1 - 2 1 0 0}$

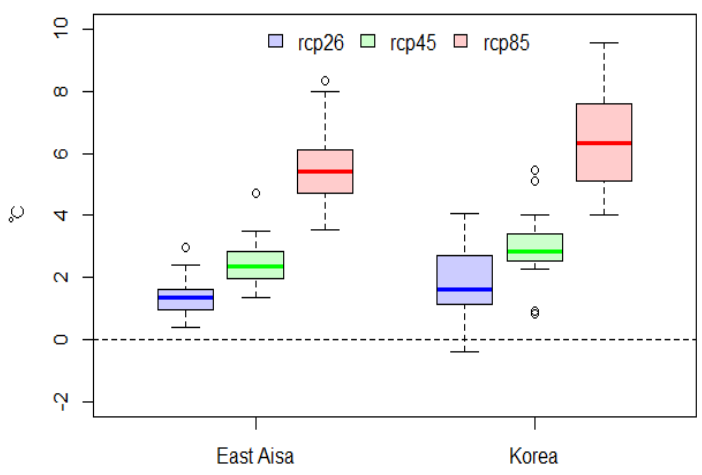

$\Delta \mathrm{TX},{ }^{\mathrm{C}}, \mathbf{2 0 1 6 - 2 0 3 5}$

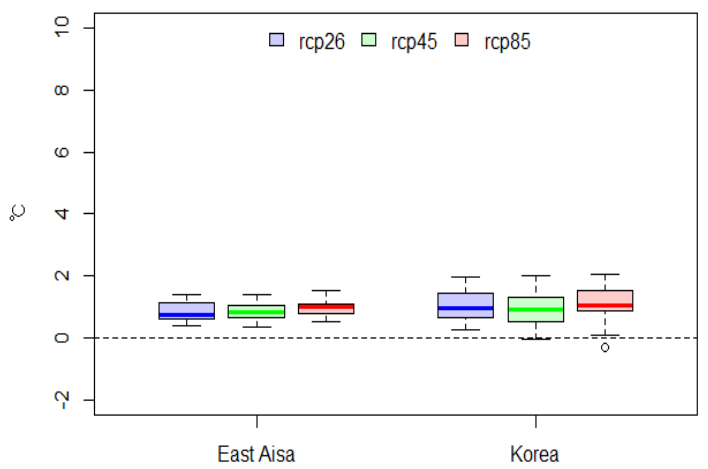

$\Delta \mathrm{TX}, \mathrm{C}, \mathbf{2 0 4 6 - 2 0 6 5}$

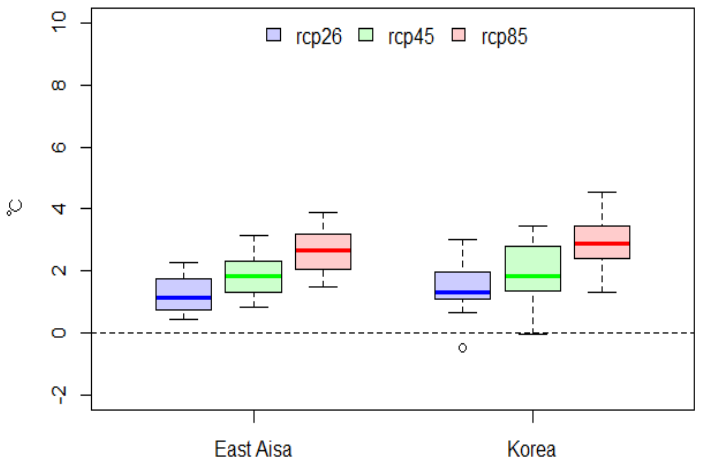

$\Delta \mathrm{TX}, \mathrm{C}, \mathbf{2 0 8 1 - 2 1 0 0}$

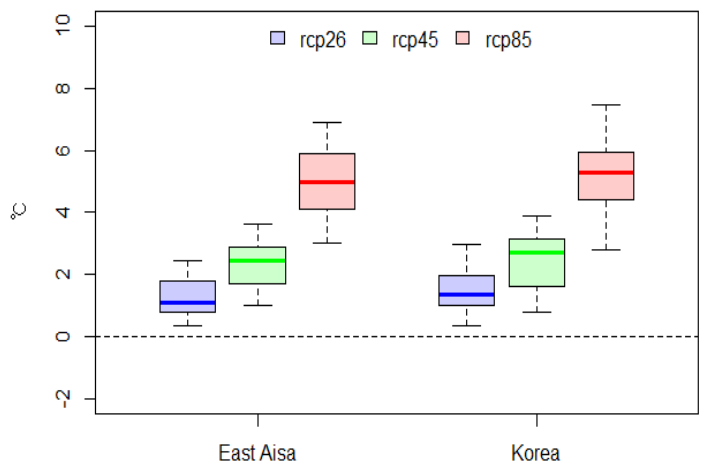

Figure 15: Box-and-whisker plots of the future changes $\left({ }^{\circ} \mathrm{C}\right)$ in averaged warm temperature extremes $\left(\mathrm{TX}_{20}\right)$ and cold temperature extremes $\left(\mathrm{TN}_{20}\right)$ as simulated by CMIP 5 models in 2016-2035, 2046-2065, and 2081-2100 relative $\$ \not \varnothing ~ 1986-2005$. 
$\mathrm{r} 26, \mathrm{R}, 2016-2035,5.114 \%$

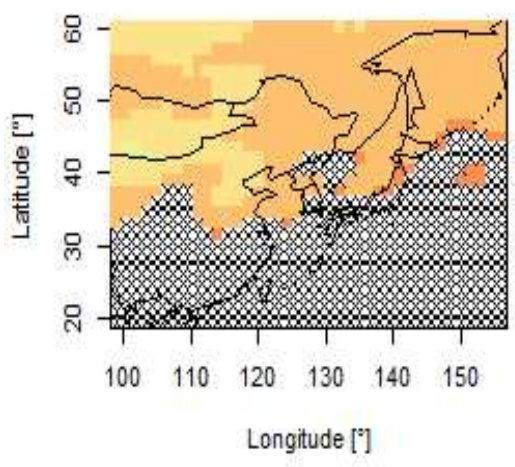

$\mathrm{r} 45, \mathrm{R}, 2016-2035,4.03 \%$

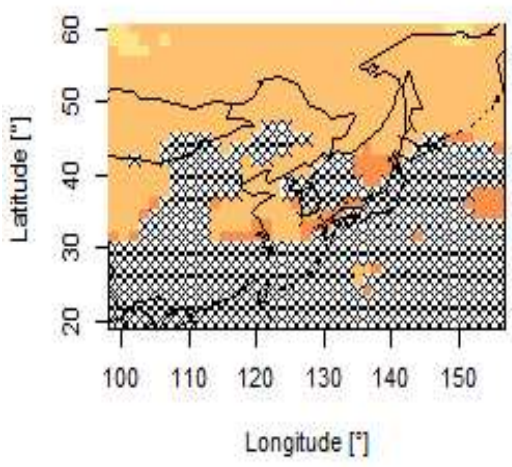

r85, R, 2016-2035, 4.283\%

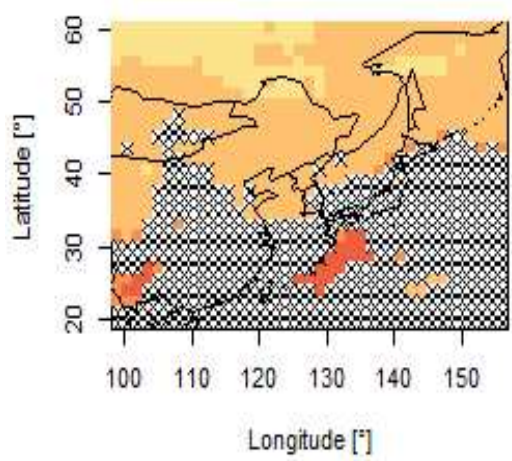

r26, R, 2046-2065, $6.266 \%$

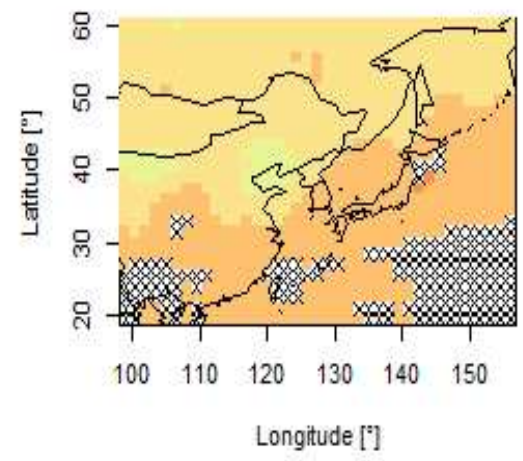

r45, R, 2046-2065, 7.082\%

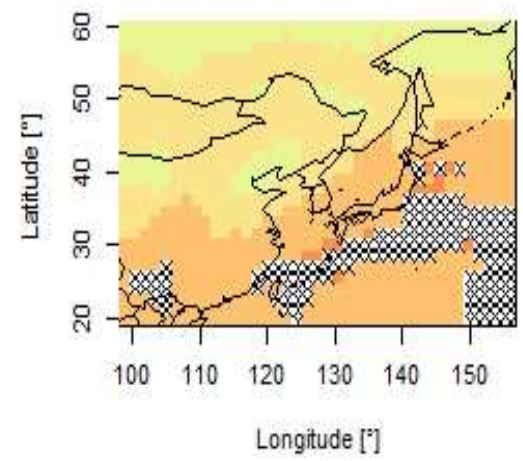

r85, R, 2046-2065, 9.334\%

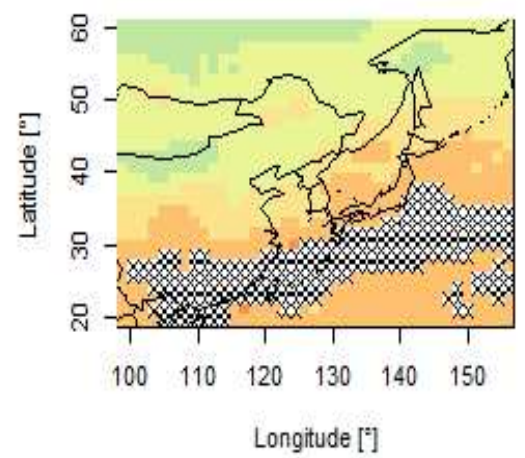

r26, R, 2081-2100, 6.106\%

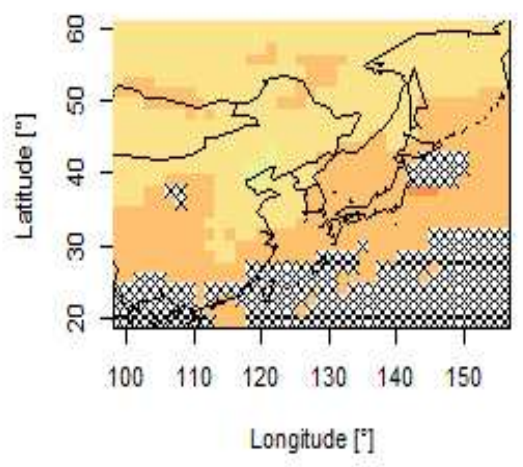

ז45, R, 2081-2100, 9.012\%

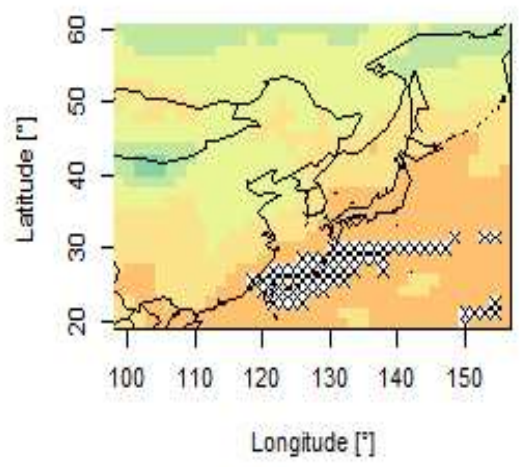

r85, R, 2081-2100, 15.559\%

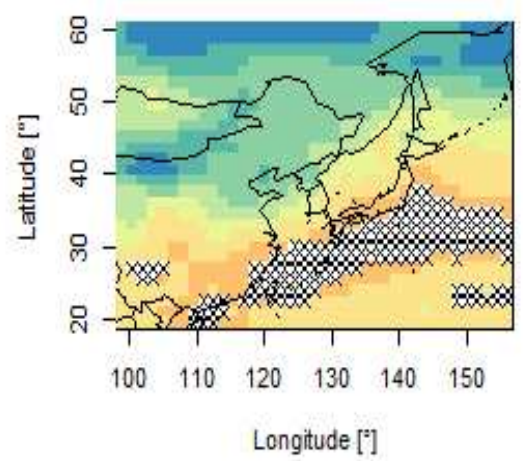

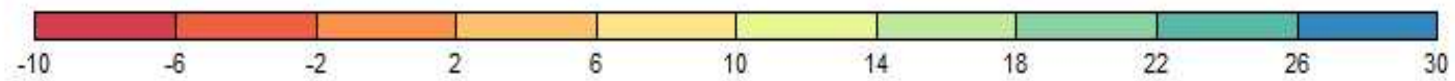

Figure 16: CMIP5 median relative change (\%) in annual mean precipitation as simulated in 2016-2035 (left column), 2046-2065 (middle column) and 2081-2100 (right column) relative to 1986-2005 in RCP2.6 (top panels), RCP4.5 (middle panels), and RCP8.5 (bottom panels). Averages of relative changes are indicated in the tiles. Changes that are not statistically significant at the $5 \%$ level are marked by cross-hatching. 

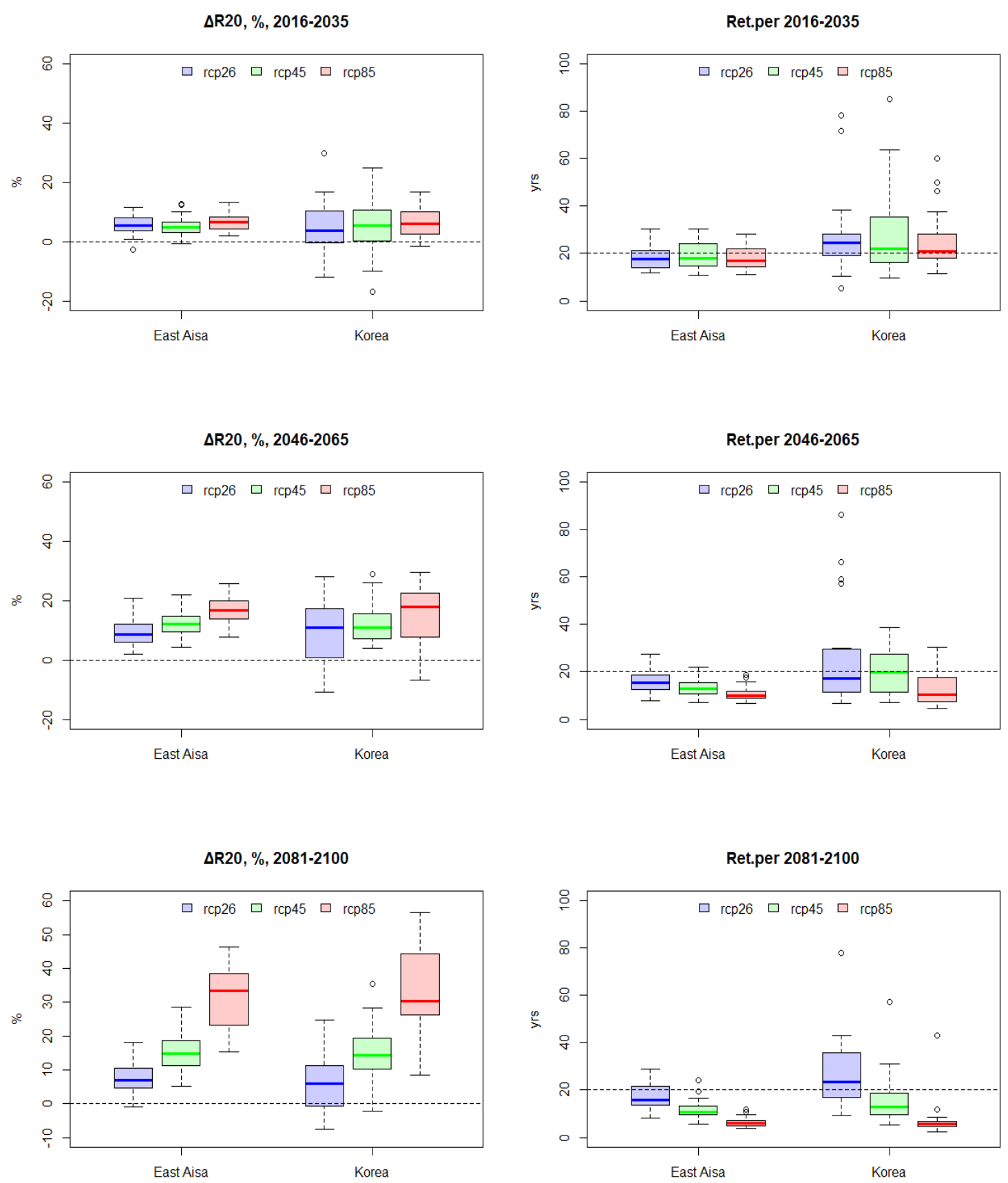

Figure 17: Left panels: Box-and-whisker plots of relative changes (\%) in the regionally averaged 20-year return levels of annual extremes of daily rainfall $\left(\Delta R_{20}\right)$ as simulated by CMIP 5 models in 2016-2035, 2046-2065 and 2081-2100 relative to 1986-2005 in the RCP2.6 (blue), RCP4.5 (green) and RCP8.5 (red) experiments. The boxes indicate the central $50 \%$ inter-model range and the median. Right panels: Same as the left panels but for regional medians of the waiting times relative to $\mathrm{R}_{20}$ of $1986-2005$. 
rainfall rates $\left(\Delta R_{20}\right)$ and of regional medians of waiting times of 1986-2005 $R_{20}$ as simulated by CMIP 5 models in the three periods relative to 1986-2005 in the three RCP experiments.

\section{References}

Coles S (2001) An Introduction to Statistical Modelling of Extreme Values. Springer, New York, pp 224.

Dee DP, Uppala SM, Simmons AJ, Berrisford P, Poli P et al (2011) The ERA-Interim reanalysis: configuration and performance of the data assimilation system. Quart J R Meteor Soc 137:553-597. doi:10.1002/qj.828

Dupuis DJ, Tsao M (1998) A hybrid estimator for the generalized Pareto and extreme-value distributions. Commun Statist-Theory Meth 27:925-941. doi:10.1080/03610929808832136

Hosking JRM (1990) L-moments: analysis and estimation of distributions using linear combinations of order statistics. J Roy Statist Soc 52:105-124.

Kalnay E, Kanamitsu M, Kistler R, Collins W, Deaven D et al (1996) The NCEP/NCAR 40-year reanalysis project. Bull Amer Meteor Soc 77:437-471

Kanamitsu M, Ebisuzaki W, Woollen J, Yang SK, Hnilo JJ et al (2002) NCE/DOE AMIP-II Reanalysis (R-2). Bull Amer Meteor Soc 83:1631-1643.

Kharin VV, Zwiers FW (2005) Estimating extremes in transient climate change simulations. J Climate 18:1156-1173.

Kharin VV, Zwiers FW, Zhang X, Hegerl GC (2007) Changes in temperature and precipitation extremes in the IPCC ensemble of global coupled model simulations. J Climate 20:1419-1444.

Kharin VV, Zwiers FW, Zhang X, Wehner M (2013) Changes in temperature and precipitation extremes in the CMIP5 ensemble. Clim Change 119:345-357.

Taylor KE (2001) Summarizing multiple aspects of model performance in a single diagram. J Geophys Res 106:7183-7192.

Uppala SM, Kallberg PW, Simmons AJ, Andrae U, Bechtold VD et al (2005) The ERA-40 re-analysis. Quart J R Meteor Soc 131:2961-3012. doi:10.1256/qj.04.176

Xie P, Arkin PA (1997) Global precipitation: a 17-year monthly analysis based on gauge observations, satellite estimates, and numerical model outputs. Bull Amer Meteor Soc 78:2539-2558

Xie P, Janowiak JE, Arkin PA, Adler R, Gruber A et al (2003) GPCP pentad precipitation analyses: An experimental dataset based on gauge observations and satellite estimates. J Climate 16:2197-2214 